\title{
Cultivation of plankton populations
}

\author{
Convener's report on an Informal Session, held on September 10, during \\ the International Helgoland Symposium 1969
}

\author{
R. J. CONOVER \\ Marine Ecology Laboratory, Bedford Institute; \\ Dartmouth, Nova Scotia, Canada
}

\section{MEASUREMENT AND SOURCES OF LIGHT}

Conover, R. J.: This is to be an informal session. I previously circulated to some of you subjects for possible consideration during this session. I do not know whether we will follow this outline, but I am going to suggest that we begin our discussions with the culture of the phytoplankton and other micro-organisms.

Several people have mentioned specific things which they would like to discuss. We might begin by considering certain aspects of phytoplankton culture and Professor Per Halldai has consented to tell us about a new radiation meter. I suggest that he leads off the session this morning and we will then see what happens.

HALLDAL: When culturing phytoplankton it is important to know what kind of light occurs under natural conditions and what sort of light we should use in the laboratory. Usually we will find that investigators carefully define their media, control the $\mathrm{pH}$ and make sure that they have the proper salt balance. However, in general, little attention is payed to the spectral composition of the light used, and, as a rule, the character of the light conditions is restricted to numbers in lux. The light from fluorescent tubes, like the ones we have in this room, is quite different from the light in the sea.

I felt that there was a great need for the construction of a portable light meter that could more easily inform us about the spectral distribution of light quanta in nature. When we have this information it should then be possible to simulate natural light conditions in the laboratory by means of an ample selection of light sources, different filters and a proper balance in intensities from the different light sources.

I will briefly describe such a device which was developed last spring at the Department of Biology, Umeå University, and which was tested this summer at the Zoological Station at Kristineberg on the West coast of Sweden. The instrument is all batterydriven and fully transistorized. It may be used in a row boat or on a research vessel. In Figure 1 is shown a photograph of a prototype of the instrument. $A$ is the sensor part containing the monochromator, the photoreceivers, amplifiers and so forth, B is the control box which controls the different units in the sensor part, and $\mathrm{C}$ is a battery- 
driven recorder. The instrument scans the main part of the visible spectrum ( 400 to $700 \mathrm{~nm}$ ). In Figure 2 are given some results from recordings with the instrument. A shows the spectral quanta distribution of light from two fluorescent types frequently

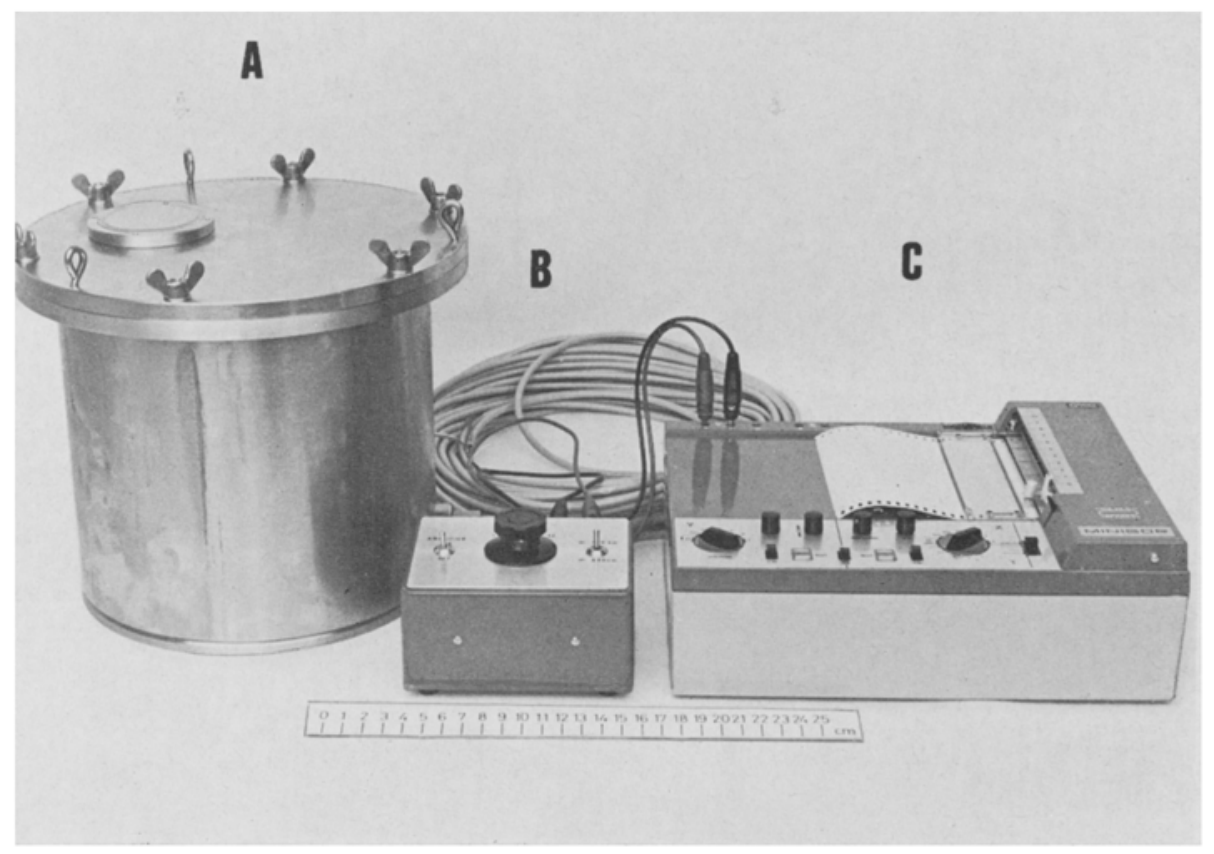

Fig. 1: The Umea underwater radiation meter. A The sensor unit containing the monochromator, the photoreceivers, monochromator drive and operational amplifiers. $B$ The control-box for monochromator drive and second deck amplification. $C$ The battery-driven recorder (HALLOAL)

used in laboratories. Note that the Hg-lines at $405,436,546$, and $578 \mathrm{~nm}$ are distinctly resolved as additional bands on top of the fluorescent light. $B$ shows measurements at night from an ordinary $\mathrm{Hg}$ outdoor illumination. The main light, as can be seen, comes from the $\mathrm{Hg}$-lines. In $\mathrm{C}$ is presented quanta distribution under overcast light conditions at Kristineberg, and at $10 \mathrm{~m}$ depth, amplified 5 times. $\mathrm{D}$ gives similar measurements during hazy sunlight conditions.

BERNHARD: Is the instrument reading in ergs?

Halldal: No, it is calibrated in quanta. $\mathrm{cm}^{-2} \cdot \mathrm{sec}^{-1} \cdot \mathrm{nm}^{-1} \cdot \mathrm{mV}^{-1}$.

BERNHARD: Can you tell us how this instrument works? Is it a photocell?

Halld AL: It has a monochromator unit, which sorts out different spectral readings, and two photocells. One Si-cell and one Se-cell coupled in parallel measure the light. The instrument is calibrated as a quanta counter. That is if we shine equal numbers of quanta at different wavelengths on the instrument the output in $\mathrm{mV}$ will be the same. When the instrument is operating the whole spectrum is scanned in less than two minutes. 
BERNHARD: I talked to Jerlov a while ago. I asked him what is the use of measuring the light spectrum in water, and he said that in normal ocean or coastal water, you can predict it. Have you tried this type of instrument in shallow waters and coastal regions?


Fig. 2: Spectral distribution of quanta recorded by the Umea radiation meter. A From 2 different fluorescent tubes. $B$ From an outdoor illumination mercury lamp. $C$ Surface and underwater $(10 \mathrm{~m})$ light during overcast day. $D$ Surface and underwater $(10 \mathrm{~m})$ light during hazy sunshine (HALLDAL)

HALIDAL: Such an instrument would be most useful in shallow waters where great variations in light conditions occur due to changes in plankton populations. The reflection from benthic algae may also be of importance. It may be possible in a rather accurate way to predict light conditions in oceanic waters. However, data of the spectral light distribution in oceanography are sparse. I feel that the safe approach would be direct measurements rather than calculations based upon assumptions.

Conover, S. M.: I have three questions. First, what is the geometry of your light collector? Is it a flat horizontal plane or a hemisphere?

Halldal: It was a hemisphere, but I have been informed by Dr. AAs at the University of Oslo, who has been working with JERLOV, that a flat opalescent plate is to be preferred. If the integrated value is wanted a certain correction factor (1.8) will 
approximately give this. The measurement of an integrated value for total radiation is very difficult. When the instrument will be available commercially, the collector will be a diffusing plate, and the instrument will be calibrated for parallel beams.

Conover, S. M.: I was wondering if you were collecting the light that was scattered back?

HALLDAL: No, the instrument functions as a $2 \pi$ collector.

Conover, S. M.: Are you, I hope, making plans to produce it?

Halldal: Yes, it will be produced by Incentive Research and Development AB, Ranhamarsv. 21, Box 11074, Bromma, Stockholm, Sweden.

Conover, S. M.: How soon?

Halldal: I don't know, I am going to discuss it next Friday. (Added later: Incentive may inform you on delivery time.)

BERNHARD: What is the price?

Halldal: According to some estimates it may be possible to keep the price within $\$ 2,000$; this will not include the recorder.

Conover, S. M.: It has been found by plant physiologists that light of certain wavelengths will do certain things for plants. For instance, blue light has been reported to enhance protein synthesis. Are you planning to work on the effects of different wavelengths of light on things like pigments or nitrogen assimilation?

HALLDAL: There is actually very active research on this current problem. As you mentioned, it has been discovered that you can control the protein/sugar $/ \mathrm{fat}$ balance by the use of different colored lights. In certain plants, blue light greatly stimulates respiration. As you see, there are many different effects of different wavelengths of light. This is why it is so important to clearly specify light conditions under which you grow your cultures.

BOALCH: Why do you limit the spectral range to above $400 \mathrm{~nm}$ ?

HALIDAL: Unfortunately we cannot detect ultraviolet radiation with the instrument. This is due to the monochromator unit. Ultraviolet radiation is important in pure oceanic waters. In coastal waters the ultraviolet radiation is rapidly absorbed due to the presence of yellow substances. Special instruments similar to this one may be constructed to cover certain parts of the ultraviolet region.

BoAlch: We have evidence that fluorescent tubes can produce ultraviolet light at levels dangerous to cultures.

HALLd AL: True, some of the ultraviolet Hg-lines go through the glass of the tubes. Ordinarily, damaging effects are not observed from fluorescent tube illumination, but sometimes it occurs. I think that the spectral region of laboratory radiation meters should be extended also to include the ultraviolet region, but the task is not an easy one.

Costrow: For a number of years, largely in connection with our program of culturing decapod larvae, we have been using a light made by an American firm which is almost exactly the same as daylight. The light, a combination of fluorescent and incandescent bulbs, is known as "Macbeth Examolight $\left.{ }^{(}\right)$", manufactured by Macbeth Daylighting Corporation, Box 950, Newburg, New York. The only deficiency has been that the lights have approximately $1 / 10$ th the intensity of natural daylight. So far, this has not been any real problem. I have rationalized the situation and con- 
cluded that in the Newport Estuary, Beaufort, at approximately $1 \mathrm{~m}$ depth, the natural daylight is far less than $1 / 10$ th the light intensity at the surface.

Conover, S. M.: At different depths, at different times of the day and under different water conditions, both the intensity and the quality of the light will be different. Has anyone any good ideas how one might imitate these under artificial conditions for growing phytoplankton?

HaLldal: This is a very important point. We should have information on spectral quanta distribution both at different depths and times of the day. On this basis, we may start simulating these changes in the laboratory. Such an approach may raise some serious technical problems, but in theory a preprogrammed system of this type is possible to arrange.

SMAYDA: There is a fluorescent light called "Natur-escent ${ }^{\circledR}$ ", which is manufactured by Duro-Lite Lamps, Inc. of Fairlawn, New Jersey, USA. It supposedly simulates natural outdoor light in emission and proportionate spectral values very closely, and has a chromatic index scale rating of $91 \%$ in the visible range, which compares with $100 \%$ for outdoor light. These characteristics would recommend its potential use over the usual fluorescent tubes in culturing phytoplankton.

WICKSTEAD: We have been talking as though light did not penetrate below $10 \mathrm{~m}$. What about the distribution of light in the tropics where light penetrates much deeper?

Halldal: Outside the continental shelf, in oceanic water, the light penetrates to considerably greater depths than near the coast. $10 \%$ of the blue light may be found to $100 \mathrm{~m}$ or more. In coastal waters nearly all the blue light is rapidly absorbed due to yellow substances. Even ultraviolet radiation penetrates to considerable depth in oceanic water.

WICKSTEAD: I am thinking of more specifically the tropical coastal waters where you get blooms of phytoplankton like pea soup. You would not get very much light at depth.

Halldal: The light that gets through a phytoplankton bloom will depend on the organisms causing the bloom. If it is a green alga, the blue and the red part of the spectrum will be absorbed first. During blue-green algal blooms, both blue, green, yellow and red will be absorbed. During very heavy blooms, even total absorption of all visible wavelengths is expected to occur.

ReEve: In this regard, have you considered means to extend the working depths of the instrument?

Halidal: The prototype was designed to a depth of $50 \mathrm{~m}$. According to my information, there is no problem to design the instrument to take the pressure at $500 \mathrm{~m}$.

BERNHARD: How sensitive is the device?

HALLDAL: I can give you an example. Last summer, it was possible for me to record the spectral distribution of quanta at a depth of $10 \mathrm{~m}$ half an hour after sunset at Kristeneberg.

\section{CHEMOSTATS AND MICROCOSMS}

Conover, R. J.: At this point, I am wondering if we could delve a little more into the actual culturing of micro-organisms. $I$, personally, am interested in the use of 
different culture mechanisms. The chemostat is certainly one which is becoming increasingly popular and I wonder whether anyone here would care to comment on the use of chemostats, either for phytoplankton culture or for the culture of higher organisms. Dr. Michael Droop has recently been exploring the use of the chemostat for the raising of rotifers. I suggest, MiCHAEL, that you introduce your recent experimental program.

Droop: I have been using chemostats for nutritional kinetic work with algae for some years now, but, as I am talking about this on Friday, I won't say anything about it today. About a year ago, Dr. Cole of Lowestoft came with an SOS to me. They had a rotifer, Brachionus plicatilis, which they used for feeding young plaice, which grew beautifully and made wonderful cultures, but which were given to suddenly flopping down at awkward moments. I agreed to have a look so they sent me the rotifer to see what I could do. I cleaned up the rotifer and got it into a monoxenic condition, feeding on a single alga. I soon found that the secret of keeping it healthy was to keep it growing hard all the time without too much food: then it never went bad. To keep something growing hard all the time, obviously, the chemostat is the type of apparatus to employ. So we put Brachionus plicatilis in the chemostat and found that it grew quite successfully.

Then I realized that you could use this system to examine the energetics of the alga-herbivore link in the food chain. I will go through this, but it's really all theoretical because we haven't yet managed to do a run and so I can't show you any results.



Fig. 3: Flow diagram for rotifer chemostat. Assumptions: (a) No algal growth takes place between $A$ and $B$. (b) There is no negative slope in the working region of the nutrient concentration/growth rate relation. (c) Steady-state conditions (Droop)

Here is the flow diagram for the rotifer chemostat (Fig. 3). Consider the conditions within the rotifer culture vessel: perfect mixing, medium flowing in and out at a constant rate and an organism growing as fast as the nutrient concentration will let it and reaching a steady-state in which it is growing precisely as fast as it is being washed out. We have $\mathrm{D}$, the rate of dilution $=\mu$, the specific growth rate, with dimension $t^{-1}$. These are conventional microbiological symbols. The rotifer mass in the culture chamber will be designated $x$ (with dimensions $\mathrm{ml}^{-3}$ ). $\mathrm{s}_{\mathrm{R}}$ will represent the concentration of nutrient input at $\mathrm{A}$ which in this particular system is the algal mass (in $\mathrm{ml}^{-3}$ ) and $\mathrm{s}$ will be the output of algae at $\mathrm{B}$ (also in $\mathrm{ml}^{-3}$ ). Now I introduce the symbol $\phi$ which is a dimensionless net conversion factor. Finally, you have $\mathrm{E}$, the maintenance constant ( $w i t h$ the dimension $t^{-1}$ ). 
Uptake by the rotifer leading to growth would be $\mathrm{x} \phi \mu$ (in $\mathrm{ml}^{-3} \cdot \mathrm{t}^{-1}$ ) and that leading to respiration, etc. would be $\mathrm{xE}$, so that gross uprake would be $\mathrm{x} \phi \mu+\mathrm{xE}$, or $\mathrm{x}$ $(\Phi \mu+E)$ (also in $\mathrm{ml}^{-3} \cdot \mathrm{t}^{-1}$ ). The rate of entry of algae into the rotifer growth vessel is $\mu \mathrm{s}_{\mathrm{R}}$ and the rate of algal outflow $\mu$ s (dimensions, $\mathrm{ml}^{-3} \cdot \mathrm{t}^{-1}$ ).

Now, in the steady state situation algal input equals gross uptake by rotifer plus algal output. Substituting mathematical expressions for the word equation, $\mu s_{R}=x$ $(\phi \mu+E)+\mu$ s. On rearranging, you get $\frac{s_{R}-s}{x}=\phi+\frac{E}{\mu}$. This linear relationship between the different parameters is also shown in Figure 4 . So keeping $s_{R}$ constant you measure $\mathrm{s}$ and $\mathrm{x}$ for different values of $\mu$ and by plotting $\frac{\mathrm{s}_{\mathrm{R}}-\mathrm{s}}{\mathrm{x}}$ against $\frac{1}{\mu}$ you can obtain $\phi$ and $\mathrm{E}$.

Now somewhere in all this, you should see that the physical meaning of $E$ is the amount of energy needed for respiration. If you decrease the dilution rate in your rotifer chemostat to such an extent that all the input energy is used in respiration, you



Fig. 4: Relationship between specific growth rate of the rotifer (dilution rate) and algal input for the rocifer chemostat (Droop)

are at the compensation point, $E / \phi$. If you further decrease the input you will not be able to maintain your animal. Three basic assumptions are implicit in this model: (1) There should be no growth of the algae in the rotifer chamber and, of course, (2) there should be no reversal of slope in the working region of the nutrient concentration/growth rate relation, and, (3) a true steady state must be attained.

In conclusion, the type of apparatus needed is an algal chemostat and a rotifer chemostat, separated by a sensing device that will dose algae and culture medium in whatever proportions necessary to maintain a constant algal concentration, whatever the flow rate you impose on the system. I won't go into the physical details of the dosemeter.

Conover, R. J.: I am very interested in this device because such a system might 
allow you to get out constants which would be useful in dealing with various other models.

Droop: Of course, the rotifer is a very simple type of animal. It has a doubling time which is less than a day. In principle, with a continuous system, one should be able to find out how much of the food is used for respiration and determine the efficiency of energy conversion. But the useful thing about the system is that it lends itself to Michaelis-type kinetics and linear regressions, which can be handled statistically. One can measure so many parameters in this way.

Conover, S. M.: I am curious about the respiration term. Isn't it perhaps better to call it catabolism? In other words, doesn't it include both respiration and excretion?

Droop: We had to make a lot of simple assumptions. Yes, it's everything ingested by the organism but not used in growth. I believe that a small animal like this rotifer, which can be thought of as a micro-organism and treated as a micro-organism, should be very useful in setting up model systems. Perhaps if one can do this with rotifers, one ought to be able to do it with Calanus, but I don't know. Dr. PAFfenhören's paper (PAFFenhöfER 1970), which we had yesterday, seems to be an advance over anything else that has been done in this line with Calanus belgolandicus. However, it is simplest in the first place to choose an animal that will perform the way you want.

Heinle: I am curious about the physics here. Do you run the algal chemostat at a rate that you have predicted from the equation?

Droop: It's rather more complicated than that. Let's refer back to Figure 3. I have an algal chemostat ("Algal culture") which has worked satisfactorily for some time. The rotifer is in the "Culture vessel". Here we have a "Medium" reservoir and here the "Sump". Now here in the centre is the "Dosemeter"; this is operated by a fairly complex program, the net effect of which is that at fixed intervals it senses the algal density in the chamber and decides whether to dose an aliquot of algal culture or an equal aliquot of culture medium. We have effectively, in the long run, constant flow and constant food level. Both the interval and aliquot size are adjustable at will, as is also the algal density setting.

HeInle: Did you alter the flow rate?

Droop: We are operating the algal chemostat quite independently of the rotifer chemostat flow rate. You can set your algal chemostat however you like within limits. In fact, you don't even need a chemostat; it could just as well be a batch culture supplying the algae. A chemostat, however, is less trouble than batch cultures.

PAFfenhöfer: I wonder what would happen in a chemostat in which ciliates are feeding on protozoans. What will happen if the excrements of the ciliates accumulate? This fecal material may not harm the ciliates but there is the possibility that they may feed on their own excrements.

Droop: Yes, this is a possibility. I don't know what to call it, but you actually get a mass of algal junk at the bottom of the sump, but not in the culture vessel, which is, I suppose, fecal material. This is a bacteria-free system, so it shouldn't be affected in that sense, but I think it would have to be taken into account eventually.

Bernhard: How long do you run these experiments? A few weeks?

Droop: Oh no, these go on for months. You see, since you want to get a regression, you alter the flow rate, and after each alteration, it is going to take a week or two to 
reach equilibrium. Then you take some readings; that is, you determine $x$, the amount of rotifer, and $s$, the concentration of algae coming out. You already know $\mu$, the dilution rate, and $s_{R}$, the concentration of algae going in. So you have one or two points on the curve (Fig. 4). Then you alter the flow rate in the rotifer vessel just a little bit and when equilibrium is reached once again you get some more points.

We haven't actually got this particular system into operation yet*. I took the summer, designing and making the electronics for it. At first I tried a series alga/rotifer chemostat, but getting the relative volumes of the 2 growth vessels right was too difficult and the system proved to be unstable.

BERNHARD: How successful is your algal chemostat? We have worked with chemostats for many years and there is always some trouble.

Droop: I have no troubles! Of course, one has had one's troubles, but I have a chemostat system now which enables me to study the kinetics of growth and nutrition. It took quite a few years to evolve (Droop 1966, 1968). I started with the conventional sort of set-up and then simplified, simplified and simplified; so a lot of the snags have been worked out. It is a very simple affair and very reliable. You've got to have a little patience. These experiments can take 9 months to do. You can spend months and months tinkering around if the organism is unfamiliar. Suddenly everything is right and you get masses and masses of information in quite a short time.

Conover, S. M.: Would you care to comment on the type of problem for which you feel the chemostat is best suited? Or, do you think it is the best thing for everything?

Droor: No, it is not the best thing for everything. It does enable you to get a relation between nutrient concentration and growth. It will, or should, enable you to measure the rate of uptake, because if the dilution rate is $\mu$ and the nutrient concentration $\mathrm{Q}$, the rate of uptake will be $\mu \mathrm{Q}$. I use them for studying nutrient limitation. They are useful, of course, for obtaining materials in a constant physiological state. A chemostat, of course, is a statistical instrument and, therefore, your algae are in a random state of cell division; that is, they are not synchronized in any way; so the measurements you make are for the average of the whole life cycle. What would be nice to have, would be a synchronous chemostat. It should be possible.

PAffenhöfer: Robert Hamilton, Institute of Marine Resources, La Jolla, has carried out experiments with the ciliate Uronema sp. feeding on bacteria. Uronema would not start feeding unless the bacteria concentration was one million cells per $\mathrm{ml}$ or higher. Did you find a certain concentration level at which the rotifer starts feeding?

Droop: This, again, is a matter for discussion. PArsons et al. (1969) at Nanaimo found a concentration for copepods below which they would not feed. We haven't as yet got this far with the rotifer, though the minimum food level looks to be quite low.

Conover, R. J.: This seems to be a very high level of food to initiate feeding. Is this level found in nature?

Paffenhörer: Yes, but only occasionally. Uronema was found, according to Hamilton \& Preslan (1969), 150 miles west of Baja California where a phytoplankton bloom was followed by a bacterial bloom, which was then followed by a Uronema

" Note added in proof: We are now obtaining data with the rotifer chemostat. 
bloom. Uronema seems to appear only for short periods when they encounter high food concentrations. I tried several times to feed Uronema to Calanus belgolandicus nauplii but could detect only very slight or no grazing at all.

Conover, R. J.: What is this ciliate? Is this one that is normally pelagic?

PAFFENHÖFER: Yes, Uronema is a pelagic ciliate.

Conover, R. J.: A number of us here are concerned with problems related to pollution and other modifications of the environment due to human activities. Is there a type of chemostat that we can use to assay various types of toxic substances? I would like to stress the importance of planktonic organisms and micro-organisms in general, which have rapid turnover time, for testing toxic materials, especially at low concentration, for a number of generations. Would anyone care to make any comments about this? Is there anyone who has used a chemostat to assess the survival of organisms in different types of stress conditions?

BERNHARD: We have been using chemostats for five years and it's not a very easy thing to do. Certain things may leak out of the tubing and accumulate after some time. We had a problem with Coccolithus buxleyi. It was growing well and then we found it was full of flagellates, which later proved to be the flagellated state of $C$. buxleyi. With this certain set of conditions, we could only get one stage of the life-cycle, the flagellated stage. Sometimes the culture dies out for unknown reasons. You can change the flow rate or do everything you can think of, but the organisms won't grow anymore; they just die. Mixing is also a problem because some algae attach to the walls; then, you have to be very careful or you get pieces of algae torn from the walls of the vessel.

Conover, R. J.: It is used extensively for bacterial culture. The chemostat works well with organisms that have a fast turnover. Obviously, you can't run experiments in a chemostat with, say, vertebrates as this would be a rather long-term operation.

Zinlioux: You asked about the use of the chemostat for the study of pollution. This was part of the rationale for my design of a multiple unit copepod culture system (Ziluroux 1969, Zillroux \& LACKIE 1970). I did this work at the National Marine Water Quality Laboratory in Rhode Island whose primary function is the study of effects of pollution on the estuarine and marine environment. I designed a multiple tank unit so that we could use some of the tanks as controls while other tanks would be available for continual, metered additions of possible toxicants or pollutants. Normally, all effluent water from these tanks is processed through filters and a foam separation device and recirculated through the system. For bioassay application only control tank effluents would be recirculated while the experimental effluents would be routed to waste. The flow rate of total waste effluent would equal the rate at which fresh medium would be metered into the system. The fresh medium would mix with the recirculated medium in a reservoir tank prior to delivery to the culture tanks. In this way, the basic medium constantly entering both experimental and control tanks would be identical and you would therefore have a much better control than with a comparable series of static tanks. The system hasn't actually been used in this way but it was designed with this application in mind.

Conover, R. J.: I am wondering whether you could use the system for long term studies with sub-lethal concentrations of toxicants. A major problem in assaying pollution is that so many of the effects are apparently accumulative. We know that certain 
substances in certain concentrations will kill an organism in a certain period of time. But there are sublethal effects which we have to worry about. Therefore, it seems almost imperative, if we are going to be concerned about these long term effects, which may take generations to appear, that we have test organisms with a high turnover rate.

ZILIIOUx: Most substances tested thus far are toxic to the copepods in a short time. We are, of course, very concerned with substances that are continually added to the marine environment at rather low levels over a long period of time. For such substances the chemostat or a recirculating culture device can be very useful.

BoAlch: Surely one of the difficulties in the use of the chemostat for testing against pollutants is that if you can grow an organism in the chemostat at all, it is usually pretty robust, something that will take a lot of bashing about, things like Chlorella, Phaeodactylum and Skeletonema. Because these will grow in anything, they are not so suitable for bioassay.

Conover, R. J.: Is there any basic reason why the design of the chemostat should not permit you to raise anything? Why couldn't it ultimately be designed to raise the most sensitive organisms? An organism in the natural environment undergoes a certain amount of turbulence, bashing about, if you like. This is a purely mechanical factor and I don't see how it can be avoided.

Hueck: In nature you have a low density of organisms but in chemostat you have a very high density; this is one of the unnatural facts about chemostats.

Droop: May I say a word about "turbidostats" in this connection? In this instrument, rate of flow is controlled by cell density. In the chemostat, you recall, cell density is controlled by the rate of flow. Under conditions of nutrient limitation the ultimate controlling factor in both systems is the concentration of the limiting nutrient. The point I want to make is that because a turbidostat is immediately controlled by cell density it is not difficult to obtain stable operation with it at near ecological densities (e. g. $10^{4}$ Skeletonema cells per $\mathrm{ml}$ ) given sensitive monitoring.

Zillioux: With my culture device I have maintained organisms through several generations that have been shown to be quite sensitive. Acartia tonsa, as well as the more robust Tisbe furcata, have been found to be at least as sensitive to copper (in the range of $15-30 \mu \mathrm{g} / 1$ ) as were several diatoms and dinoflagellates. This work was done by Dr. John Gentile at the National Marine Water Quality Laboratory. In other studies we found that Acartia tonsa was about 15 times more sensitive to crude oil and to several commercial dispersants than was Artemia salina. Tisbe furcata was about 4 times more sensitive than Artemia to dispersants tested in combination with oil.

GREve: There are two different types of systems involved here. One system is closed, and the other is continuously flowing.

Conover, R. J.: In my opinion, Zillioux's apparatus is not a chemostat. But there may be other opinions.

Droop: May I try to define a chemostat?

Conover, R. J.: Yes, please.

Droop: A chemostat is a continuous flow culture system in which the rate of flow is held constant and the population is allowed to equilibrate accordingly, control being effected by the rate of supply of a limiting nutrient. It says nothing about whether the 
system is open or closed. A fairly comprehensive review is given by HERBERT (1958) in the Stockholm symposium.

BERNHARD: There is, of course, one other problem with the chemostat. Because of the constantly renewed environment, the phytoplankters are always growing at high rates, that is, in the logarithmic phase. In the sea not all algae are growing at the logarithmic rate.

HUECK: Another difficulty with the chemostat is that everything is in a state of equilibrium. In a natural population, for instance, there are the annual shifts in input and output.

HeINLE: I would like to say a little about equilibrium in the zooplankton population that I studied during the summer months, that is for five months of the year. While they replace their biomass every day and half to two days, the population size, that is the standing crop, stays roughly constant.

BERNHARD: Are you doing this in the sea?

HEINLE: In an estuary, the Patuxent Estuary.

BERNHARD: I asked because several people* have tried to follow plankton patches with all kinds of parachute drogues and things and didn't have good success.

Heinle: Our area is enclosed on three sides. You just bave to take enough samples.

Conover, S. M.: I think you really do have a special system here. Your area is ideal for this sort of study.

Conover, R. J.: With all due respect to the chemostat, I think we have also pointed out in our discussion that the environment is different in many respects. You usually think of the chemostat as involving one organism and its nutrient supply in a constantly flowing system. The complexity of the chemostat increases markedly as you increase the number of steps or organisms in the device.

A number of people have been interested in the microcosm or microecosystem. I wonder whether we might discuss this area for a few minutes. Although we may still not be dealing with a system directly comparable to nature, perhaps in some cases the differences are not so great. We generally assume that a microcosm will eventually reach some sort of a natural steady state under the conditions that are imposed on it by the investigator or by nature.

Microcosms or microecosystems are basically of two kinds. In one type the investigator chooses the organisms for instance, a bacterium, a protozoan and a copepod and puts them all together to see what happens. In other words, the organisms are not "naturally selected", but artificially introduced. This is the gnotobiotic type. In the other type, you take water with its natural fauna and flora and impose certain conditions. It can be some sort of flow-through system or it can be static; but nature chooses the organisms. The environment will eventually reach some sort of steady state for the situation with which you are dealing. Then you can impose a new condition or set of conditions on it until the steady state is again established. In this way perhaps you can learn something new.

* Presentations by C. B. Miller and by R. J. Conover and subsequent discussion at the International Association of Biological Oceanography meeting, "Design and Analysis in Plankton Sampling", Woods Hole, May 21-24, 1968. 
ZiLlioux: I don't particularly care what I call my system but I'd like to call it something. It fits most of Michael Droop's criteria for a chemostat, but it has bacteria, protozoans and copepods in a steady state and may be a microcosm.

Conover, R. J.: I personally would lean slightly toward the microcosm only because of the way you set up the system. It might be readily converted to a chemostat by introduction of a constant flow rate that would control the rate of production or the concentration of the animals.

ZiLlioux: The food is introduced at a constant rate, that is at regular intervals. The mean phytoplankton concentration is, therefore, kept constant while the zooplankton concentration reaches equilibrium with a constant ratio between adults and relative numbers of the various developmental stages.

Conover, R. J.: In all probability then you could treat it as a chemostat.

TRANTER: I would like to draw attention to the possibilities of working with the second of the two types of ecosystem defined by the Chairman, namely, the one in its largely natural state upon which one sets conditions. Such conditions are often set by industry - e. g. powerhouses discharging heated effluent into a nearly natural system. Professor EISNER of Strathclyde University has recently described a strategy for experimenting with such systems. Because the strategy demands that experimental manipulation of such industrial discharges be slight, co-operation from industry in such experimental programmes is feasible. The strategy consists of feeding into the system a "signal" in such a mathematically well defined way that the "response" may be identified from the ambient "noise".

\section{MODELLING THE ENVIRONMENT IN THE LABORATORY}

Conover, R. J.: Dr. Smayda has some comments on the problems of application of laboratory derived data to field conditions.

SMAXDA: One important reason for carrying out field and laboratory investigations on the dynamics of population growth is not only to be able to make some sort of quantitative statement about the factors responsible for the development of phytoplankton at a specific time, but to go beyond and make a predictive statement about what will happen given certain environmental parameters. There are inherent pitfalls in this kind of an approach. Two vital assumptions are necessary: first that one can correlate the seasonal fluxes in phytoplankton abundance and species' composition with the environmental parameters that are being measured; and secondly, that one can use the results of in vitro culture studies to help to explain the dynamics of those communities. I would like to touch just briefly on both of these assumptions primarily because of an inherent dilemma in this kind of approach, and suggest that we share our experiences and ideas.

The classical idea that one can relate the particular measure of phytoplankton abundance used to whatever environmental parameters are measured has not really been tested. There are strange or ecologically misleading relationships in the environment, insofar as cause and effect are concerned, such as the phosphate-blue whale correlation in the Antarctic: where you have little phosphate, you have a lot of 
whales, and vice versa. We know that this is not dynamically correct because whales are not using the phosphate. But when you get into the microbial world, it is very easy to make this kind of spurious correlation of cause and effect. We have undoubtedly in the study of phytoplankton similar kinds of 'whale-phosphate relationships' of which we are not aware: the problem is to be able to recognize the "whale-phosphate relationship' for what it is. We must be able to say that these factors are irrelevant, or those relationships are fortuitous or second order.

I have tried to examine the general notion that we can relate phytoplankton abundance and species selection to the traditional hydrographic and chemical observations customarily made in such studies. I performed some bioassay experiments about which I will be reporting tomorrow. What emerged, using four different bioassay diatoms (and we have now expanded this considerably), was that there was no correlation between the bioassay response and any of the hydrographic observations that were made. One could not predict the effect of given nutrient on growth from in situ analyses of availability; nor could one predict the response of any of these species from an analysis of the water column by making the traditional physical and chemical observations nor, from a knowledge of the response of one species, predict that of another. I am not making a general statement, but I am saying that this is our experience which prompts my concern about the limitations of this particular, traditional working hypothesis.

We then went to the other approach. Because we couldn't explain why we observed certain kinds of events in tropical and temperate waters, we selected various species and studied them in vitro to try to account for their seasonal dynamics. We started out with Detonula confervacea which has a very peculiar distribution. It is part of the arctic flora found in Narragansett Bay, which is roughly $41^{03} 0^{\prime}$ North. In nature Detonula invariably disappears at about $3.5^{\circ} \mathrm{C}$.

There are some very enigmatic features of its distribution. We, as biologists, have traditionally believed that we can group phytoplankton in terms of biogeographical classifications on the basis of their temperature preferences. We speak of arctic species, boreal species, and so forth. I grew Detonula under the conditions of continuous light, which is an artificiality, for a five day growth period, with different combinations of light, temperature and salinity. The temperature response is shown in Figure 5 which gives the mean division rate during $\log$ growth over the 5 day period plotted against temperature; at $2^{\circ} \mathrm{C}$ the rate is $\sim 0.6$ division/day; it increases to approximately 1.5 at $12^{\circ} \mathrm{C}$. At warmer temperatures the population collapses. There is no growth at $16^{\circ}$. On the basis of this, it's obvious that Detonula is not cryophyllic, but rather has a wide thermal range in which it will grow happily. It cannot be temperature, it would appear, which is responsible, as was previously thought, for the seasonal cycle of Detonula confervacea, nor does temperature explain its distribution or cycle elsewhere.

So we then went to another diatom Rbizosolenia fragilissima. There is some confusion over this particular taxon. Another species, $R$. faroensis, has been described on the basis of its being slightly wider. Both forms occur in Narragansett Bay even though Husted $(1930)$ argues that there is only one species $-R$. fragilissima. Anyway it grows from $<2^{\circ} \mathrm{C}$ to about $29^{\circ} \mathrm{C}$ in nature; but in the lab, with various isolates, we cannot get Rhizosolenia fragilissima to grow below $9^{\circ} \mathrm{C}$ even with a large number of 
different combinations of light, temperature and salinity. Obviously, on the basis of these experiments, as with Detonula, we cannot account for the behaviour of this Rbizosolenia in Narragansett Bay.

We then went to Skeletonema costatum which is eurythermal. There is some problem as to whether we were working with one or two forms. At roughly $35^{\circ}$ North we have something called Skeletonema tropicum. If you believe that the difference between two chloroplasts and four chloroplasts is taxonomically significant, then you can separate the species. If you don't believe that, then you lump them. It turns out that

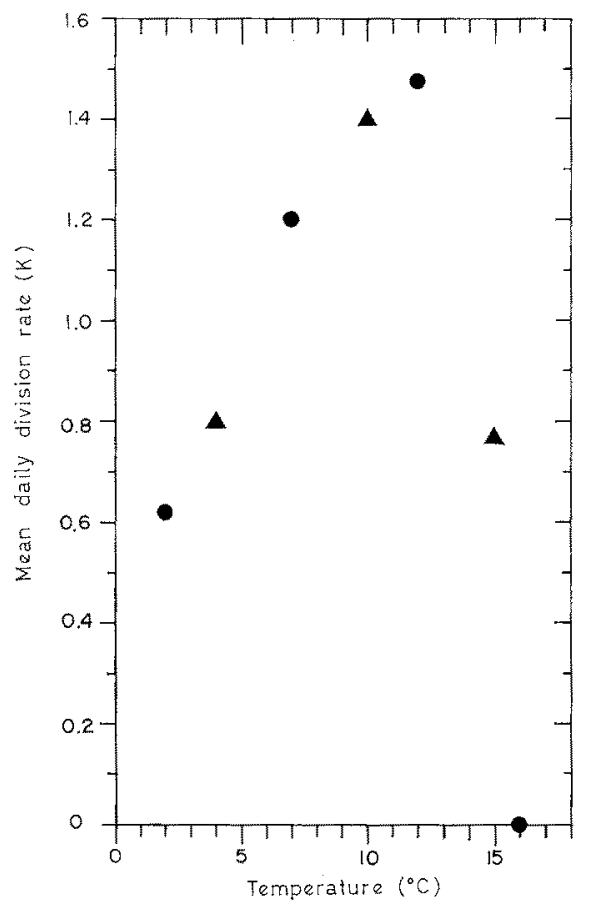

Fig. 5: Influence of temperature on the mean daily division rate of Detonula confervacea from Narragansett Bay (USA) at $32 \% \mathrm{~S}$ and $1100-1200 \mathrm{ft}$-c, as reported by SMAYDA (1969)

in Narragansett Bay, as in many other areas, Skeletonema will grow exceptionally well at zero degrees. However, it is only with an awful lot of coaxing that one can get Skeletonema to grow at these very low temperatures in the lab. If you look at some of the laboratory studies done with Skeletonema, as BraARud (1962) has, you have a completely erroneous picture as to what Skeletonema might do in nature.

In Narragansett Bay there is a very interesting succession between Skeletonema costatum and a flagellate of uncertain taxonomic position, Olisthodiscus luteus. PRATT (1966) has reported that Olisthodiscus liberated substances which would inhibit the growth of Skeletonema under one set of conditions but under other conditions would stimulate the growth of Skeletonema. We have been working with another clone of 
Olisthodiscus isolated in a different year and did not find the same effect. We are now trying to confirm that this is independent of differences in technique.

What I am beginning to wonder about is the extent to which we can rely on all these individual studies to try to account for ecological events, and therefore, the feasibility of our second working premise, namely, that a knowledge of in vitro behaviour can be used to account for in situ responses. Obviously, to date we have not been particularly successful for reasons which are uncertain. What I am saying is not really new, but it is becoming more and more critical for ecologists who are searching through literature looking for an explanation of the disappearance or seasonal changes of some species. Is it possible that we are really dealing with a tremendous plasticity in the physiological responses of these phytoplankton, which can truly be considered as clones, and, if so, where do we go next? The obvious answer is to take each one of these organisms and study it in great detail, but it would be the year 2100 before we would have the observations to be able to really make quantitative statements. Do we need a conceptual breakthrough, or perhaps a reconsideration of our working hypothesis about how we should view and measure the diverse phytoplankton-environment inter-relationships?

CoRKETT: I would like to follow up your suggestion of the importance of in vitro studies to describe ecological events. I am a zoologist and so I will give an example from zoology but perhaps I might try to make a very generalized statement which may help us in discussing this problem. If we are going to study the rate of any biological process, for example, the development rate of copepods, we might write it like this:

$$
\frac{d D}{d t}=f(T, S, P \ldots)
$$

We say that $D$ is a function of the environmental parameters. The important factors in this case might be temperature $(T)$, salinity $(S)$, pressure $(P)$, etc. and just as in the physical sciences, we can write formulae for these functions. This is what I call a physiological response, one which can be described by an equation, an example being the development of eggs to hatching by my copepods because they respond directly to the physical parameters of the environment; hence they fit the physiological formula.

Now, if we go a little higher in the life cycle of the copepods and consider the larval stages, we can again describe their development rate as a function of the physical parameters $\frac{d D}{d t}=f\left(T, S, P, \ldots X_{1}, X_{2}, \ldots\right)$, but we have to add a new set of terms $X_{1}, X_{2}$, which can be called "quantities". These are all measured in units of energy or mass or some such thing. They are totally different from the physical parameters and, of course, a good example is the food supply. This sort of generalized formula is derived from earlier consideration of these matters by LOTKA.

In theory we could describe each quantity in this equation by another whole set of physical parameters, but under these conditions we would get a very complicated machine. We all know how very complicated it would become from our experience, for example, to describe completely the food supply of a copepod in physical terms. What one has to do is to recognize that these two sets of values exist and make use of them in whatever way one can. If some of you went to my earlier talk, you remember 
that I first tried to relate the physiological response of my eggs to certain parameters and then developed the relation so that I could also use it under certain conditions, such as when food is non-limiting, with the later stages. So I can write a similar formula for development of larval stages under these very specific conditions.

I don't want to say very much more except to make the comment, that if you are working in vitro and wish to use the results for prediction you have to be able to write a reasonable equation or describe your results in such detail that an equation could be written. Now there is one other point which can be raised here when considering the correlation between two types of results. There may be a good physiological reason for the correlation between two variables, but even if the relationship is not one of cause and effect (the whales aren't feeding on phosphate), nevertheless, the relations might be used to make a mathematical model and to approach, in a generalized way, the condition which would enable you to predict from the laboratory to the field. This sort of approach is used by mathematicians and systems analysts in industry to make mathematical models for cost effects of their manufacturing processes.

GoLD: I would like to comment on the ecological implications of TED SMAXDA's data and how they might be applied to the field. I don't think it is as hopeless as it may look, because there are some interesting questions which have been raised right here. To me, the question of the nutrition of the organisms under your particular culturing conditions is pointed up. I wonder, perhaps, if slight modifications in the medium such as different ratios of nutrients, additional trace substances, etc. might not change the tolerances to other environmental parameters (see e. g. Gold \& BAREN 1966). Perhaps the lower or upper limit of temperature tolerance, found under the conditions that you used could be changed. You sort of "tailor-make" your system to be more like what you actually see in the environment.

SMAYDA: Certainly by altering the physical or growth conditions, I could alter the shape and type of response. For example, if $\mathrm{I}$ add more nutrients for Detonula, I can probably push that $12^{\circ} \mathrm{C}$ upper limit even higher. I know that. But the point is that I don't want to "tailor-make" the media to give me the result that the ecological data say that I ought to have. I would like to be able to perform in vitro experiments without a bias or prior knowledge about what kind of result I would like to get and, in this way, account for rather tenuous ecological relationships. That's where the problem is.

It would be nice to set up an experiment to determine definitively, for example, whether I can apply the laboratory results for Detonula to explain its strange behaviour in the Isefjord in Denmark or why it seems not to be important off the Norwegian coast. But perhaps I can only apply those numbers to Narragansett Bay because that's where my clone came from. Maybe I can only apply my numbers to my clone with its particular pre-history. We really have to know this. If it turns out that we always have to speak of different ecological strains, or physiological clones, what happens to our attempt to apply the concept of ecological unity? We are already pushing biochemical unity. We now want to say that there is ecological unity and, hence, we can take diversity indices from a terrestrial community or from the tropics and apply them to a temperate area. Instead we may possibly have a great number of 
models that are made up of views of the system which are based on artifacts. It would be nice to eliminate this.

Let me give some more examples of the type of problem with which we are concerned. It is believed that a community with a large diversity index becomes stable, more mature and is less vulnerable to catastrophic events. McAlister, who recently got his doctorate at Rhode Island, collected a series of samples, sampling as quickly as possible, just minutes apart, and then counted everything in the water bottle sample. He found diversity indices which changed from that of a pioneering community to an old stable community in less than five minutes. There is certainly patchiness here. Then another student, Krout, examined the $430: 665$ pigment ratio, which Margalef (1968) believes increases as the community becomes more diverse. A very careful study over an annual cycle taking weekly samples with a great number of replications demonstrated no correlation between the $430: 665$ index of pigment diversity and what was happening to the community in nature. Does this mean that the index of pigment diversity works only in the Ría de Vigo in Spain, and, therefore, is still valid for that environment but not for Narragansett Bay or does it work at all? In a way it boils down to the question of how we are to use the literature, and to what extent we can extrapolate.

HeINLE: I think that one of the problems here is that we are taking organisms in isolation into the laboratory and attempting to relate what we see there to the total combination of events happening in the field. Perhaps the approach should be to use experiments like these to eliminate the physical parameters that are not important. If you are looking in your cultures at phosphate for example, or temperature, a single parameter at a time, then you can at least say that temperature or phosphate alone are not critical factors. They may be working synergistically with some biotic factor.

I had a similar experience in Chesapeake Bay which has a net seaward flow of surface waters and a net upstream flow of deeper, more saline waters (PRITcHard 1967). An organism moving toward the surface would encounter fresher water but would be transported downstream to an area of higher salinity and vice versa. The copepod Eurytemora, during the summer months, is almost restricted to the upstream limits of salt intrusion. From the distribution in nature one would say that this species cannot tolerate high salinities at high temperatures. So I had a student look at the phototactic response in the lab to see whether it was responsible for the restricted distribution during the summer. A positive phototaxis at low salinities and negative phototaxis at high salinities could cause the observed distribution. The result was the exact opposite of what the hypothesis predicted; the animals moved toward the light at high salinities and the organism should have been distributed down the Bay. We then wondered if maybe the salinity shock caused mortalities. They withstood the shock of going directly from 0 to $20 \% \mathrm{~S}$ with no ill effects. So, the laboratory results contradicted field distribution and obviously the only answer is that the original hypothesis was wrong. You've got to look for some other factor controlling distribution. So then you do another set of experiments testing another factor and perhaps eventually you will find the right one.

Conover, S. M.: To elaborate a bit on the type of problems brought up here, it is quite self-evident, but perhaps needs to be mentioned again, that in a natural environ- 
ment you cannot ignore the possible effects of competition. For example, SMAYdA found Detonula to be very happy over a $12 \mathrm{C}^{0}$ range in the laboratory, and yet in the field, it passed out of the picture at temperatures above $3.5^{\circ} \mathrm{C}$. Perhaps the explanation is not different physiological clones, but rather a grazing effect which knocks out the population under this particular set of circumstances, or else a competing phytoplankter which is better able to utilize the environment at temperatures greater than $3.5^{\circ} \mathrm{C}$ than Detonula and so uses up essential limiting nutrients, eliminating Detonula.

I share with TED SMAYDA his dismay at all the problems. I can only take an optimistic viewpoint that we must continue to work under simplified laboratory conditions in an attempt to find out there what the limiting factors apparently are and then, as Don HeInLe suggests, when we think we have an answer, reapply it in the field. In the laboratory, we hope that we can narrow down to one or two critical factors. In fact, as I am sure we are all aware, the ecological situation in nature is so complex that there are many, many factors. And this is where we must all become mathematicians.

BerNHARD: This is actually a discussion on the strategy of how to do research. How many people have actually tried model building in simulation of the environment? I think that it may be a good strategy to start first by building a model and to see then, with what you know from the literature, which are the most important factors. We all know that people do this unconsciously. First, you build a model or a hypothesis, you have an idea and then you test it. In this way, you check on the model by the so-called scientific method. I think it is a good experience, if before one starts to work, he tries to figure out the way the system works. If the model says it happens in a particular way I think you will come to the conclusion that you have a good idea which are the most important factors.

One of our problems is that we want to have some predictive capability but usually we only ask afterwards with what precision we want to make our prediction. If you think about it from the beginning, you might find the answer to the problem of whether you should worry about physiological clones. You might be able to predict from the model how important physiological differences would be and how far they might influence the actual prediction of your distributional model. I think we should try the approach at the start of model building, and then try the experiments first on the computer and then in the laboratory. However, if you want to do this, you need a lot of people from different disciplines working together. If you come up with a model that is very complicated and you don't have the people, then maybe you should try something else.

SMAYda: Let me pose a practical example. Cushing (1963) says that the classical idea that the collapse of spring bloom is due to nutrient limitation is not correct (at least in the North Sea) but is, in fact, due to grazing. Perhaps Dr. Bernhard would tell us what kind of an experimental setup he might use to distinguish between a collapse being due to nutrient depletion or the collapse of the bloom being due to grazing by zooplankton.

BERNhARD: I would try to make a model and then test the model. I haven't thought about it before now and I would have to think about it. If 5 or 6 people can get together in a problem-solving group and, let their hair down, some progress can be 
made. In the laboratory we should work more together. I think the solution can be found but, of course, you must tell me what precision you wrant so that we can find out what sampling needs to be done.

CORKETT: I would like to go back to what I was trying to express before. I would say we could only make a reasonable model for the first case.

BERNHARD: Why?

CORKETT: Because there you can write the equation and if you can write the equation you can at least make a reasonable model. This is the sort of approach taken in the physical sciences. The physical sciences have got on, in many ways, much faster than biology. Biology is a much more complicated discipline than is physical science. So I would say that until we can reasonably express such a relationship mathematically, as in my first case, we can't really make a model, an accurate model, anyway. But we can, for example, specify that food is non-limiting in a model; or we can control predation in the lab either by being a predator ourselves and taking out a certain number of animals, or take some other approach, so that we can precisely define these quantities so that they can be eliminated from the model. Then we can describe a function, write the equation and, at least, approach the model situation. For example, with the copepod Pseudocalanus, I know how temperature affects development when food is nonlimiting. Therefore, I can reasonably hope to make a model, when I get enough information, that will apply a function of temperature, making such qualifications that the model only works when food is non-limiting, and that salinity, pressure and light do not have too much effect in terms of how many copepod eggs come through.

Of course, there are a lot of qualifications. It would be perhaps five years' work at least before we have enough data to describe even this relatively simple picture. So this is a very complicated system, which everybody knows anyway, but I do just want to come back again to my original equations. It is possible to construct a mathematical model, although perhaps not so precise as my copepod-temperature relations, but a general mathematical model, based on such correlations as, for instance, the whalephosphate relation. This kind of an approach is being used by CusHrng (1959) and others in constructing models for phytoplankton and zooplankton production.

SMAYDA: Dr. CoRKETT told us yesterday, or the day before, that with Isodbrysis galbana, the food workhorse in a lot of zooplankton studies, he set up a situation where food was not limiting. He got these very nice curves and I think he is really to be congratulated for it. It is a marvellous piece of work. But I am ecologist now. When I consult his data, I say to myself, Isochrysis galbana does not ordinarily occur in my area; it is a tidal pool organism. And then I remember what Dr. PAFFenhöfER said yesterday. His data showed that with Lauderia borealis, the fecundity of his Calanus belgolandicus was best. With the Gymnodinium splendens he got the fastest growth rate, I believe. And with Landeria anulata or L. borealis he got the best survival, or was it a different sex ratio? I don't remember, but anyway this suggests now that he obtains different responses, depending on the algal food source, for the same zooplankton population. Now how do I take his data and your data into consideration, and apply them to my problem concerning the extent to which predation by zoo- 
plankton is responsible for species succession and fluctuations in abundance in my phytoplankton population?

PAFPENhöper: In my experiments only one algal species was fed at a time to the copepods. In the ocean many species occur together and most of them can be eaten by zooplankton. These different species, if fed separately, may have different influences on growth, survival, fecundity and the condition of the copepods. It will be difficult even to determine the influences of the few dominant algal species on the growth of pelagic copepods.

The next step will be to offer two or three algal species simultaneously as food to Calanus helgolandicus nauplii and copepodid stages. In recent experiments $C$. belgolandicus produced only small numbers of eggs and showed slow growth when feeding on Skeletonema costatum. But if several species are offered together the result may be different.

HuEck: I would like to comment on the nature of these curves. I believe that most biologists forget that in fact they are not dealing with straight mathematics in an equation like this but that they are dealing with stochastic relations. One has only some expectancy that events will occur in this way. Even such a wild relation as the whalephosphate correlation is only a description of a mean event. There are some unlikely possibilities in the behaviour of organisms and even with a high correlation there is always a chance that the unlikely will happen. One must realize that in populations you have many millions of organisms so that the unlikely chance will crop up. Now if you have the usual Gaussian curve, you are dealing with the mean, but what about these other organisms that are not on the curve? Even if the average organism freezes to death in a certain experiment, it may be that the other factors are so favourable to it that, even with a very low chance of survival, under the same conditions it will realize a large population in nature. I believe this also ties up with what Dr. BERNHARD is saying. Within what limits of accuracy do you want your experiments? You are not dealing strictly with relations of this type as in a physical experiment. You are dealing with populations. You are dealing with a stochastic model. I believe it is possible to build a model but you need a computer for it and you need to be aware of the statistical nature of what you are doing.

GREVE: I wish to say something about the factors influencing population growth rates in Pleurobrachia pileus. First, I refer to Dr. CoRketr's equation giving the development rate as a function of the physical parameters of the environment. I am studying population interactions, in which the whole range of stages from egg to adulthood must be continuously considered when talking of the influence of any ecological factor. This ecological factor may be temperature or salinity as well as another population. A model of the relationships of Pleurobrachia pileus and Temora longicornis, for instance, has to take into consideration the age structure and the abundance of both populations. In my work, I used a model of the ecological factors influencing the population of Pleurobracbia directly to predict alterations in the population structure; the illustration gives you an idea of the way in which the simple graphical model is used (Fig. 6). The figure represents only one unit of the whole model, symbolizing the influence of adult Temora longicornis on different age groups of Pleurobrachia pileus. It can be seen from Figure 6 that an increase in the abundance of Temora has a different 
effect on young and adult Pleurobrachia: it decreases the chance of young Pleurobrachia surviving to adulthood, while it has a positive effect on the adult ones until the point of overfeeding is reached. The number of such influences equals the number of ecological factors such as temperature, salinity, Beroe, Calanus, etc., some hundreds of factors in even a simple ecosystem, which really are involved. It remains our job to quantify these interspecific or interfactorial relationships in the ecosystem. What I

a



Fig. 6: A model of the influence of adult Temora longicornis on a population of Pleurobracbia pileus. a Influence of Temora longicornis at different abundances. $b$ Effect of one given abundance (GREVE)

tried to demonstrate with this model was just one way in which the influence of the abundance of Temora on the population of Pleurobrachia may be described. Using this model at a given abundance of Temora, I get a curve like the one in Figure $6 \mathrm{~b}$, showing the direction and the intensity of the influence of Temora. From the curves of all ecological factors we can predict the total influence on the Pleurobracbia population. This simple model will only fit our empirical data and will be only as accurate as they are, and not as clearcut as a mathematical model, but it was useful in the prediction of population dynamics in the North Sea as well as in my experiments, where only a few environmental factors were important.

HeInle: I can first say something in defence of LotKa. His parameters, if CHRIs CORKETT would permit me, were originally written in probabilities, the development rate would be a function of the probability of $P$, probability of $S$, etc. (LoTKa 1925) so that this equation is strictly in a stochastic form. Realistically, even those of us who are not mathematicians can model sub-systems or parts of ecosystems as Dr. Greve has done here. 
What I was interested in was the effects of age selective predation on populations of copepods, and growing them in mass cultures, it was very difficult to go in with a pipet and catch individual Acartia tonsa in any quantity that would amount to significant predation. I did not have a good way to do this in the laboratory. LotkA's formula for calculation of age structure is theoretically well founded and widely used in biology and also in fields like chemical engineering. The same formulas apply to nuclear reactors, etc. The basic relationship is that the age structure $C_{x}=b l_{x} e^{-r x}$, where $b$ is the birth rate, $e$ is the base of the natural logarithm, $x$ is time, $l_{x}$ is the probability of survival to age $x$, and $r$ is the intrinsic rate of increase, that is, the instantaneous rate of increase in an exponentially growing population (BIRCH 1948). You can modify this by multiplying with a non-age specific mortality $e^{\text {-d }}$ such that

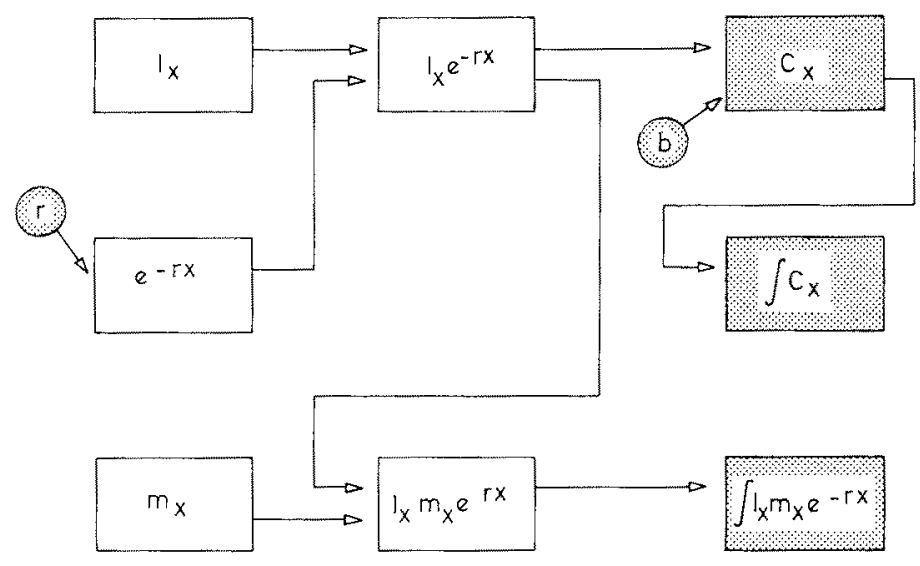

Fig. 7: Flow diagram showing the basic parts of the simulation of age structure. Inputs to the simulation are in open boxes and the solutions which were sought are shaded. (Consult LesLre \& RANSON 1940 and BIRCH 1948 for detailed explanations of the formulas) (HEINLE)

$d=r$. Then you can substitute $d$ for $r$ in the formula so that the age structure is set by the death rate. You can also do this in a more complicated way by making mortality a complex function and here is where simulation with a computer comes in.

Predation alters $l_{x}$; so for simulation, $l_{x}, m_{x}$, and $e^{-r x}$ were generated on the computer, and a means was provided for altering $l_{x}$. Figure 7 is a flow diagram illustrating the problem. The simulations were done on an Electronic Associates TR-48 electrical analog computer. For details of the simulations consult HeINLE (1970). Two simulations were done. One involved wild populations of Acartia tonsa and the entire diagram shown in Figure 7 was used. In the second case I was modelling a laboratory population where $I$ had a direct measure of $b$, and $r$ was zero. I could, therefore, eliminate a large part of the circuit (the bottom 3 boxes in Fig. 7). Mortality was applied either to juveniles or adults or to combinations of the two. Experimental survivorship of Acartia tonsa and fecundity of Eurytemora affinis were used, so the data aren't from the same species, but they are real. Four schedules of predation were used. The resulting age structures are shown in Figure 8 . In all cases predation was increased until 
$r=0$. Nonselective predation (schedule 1) caused an age structure that resembles a negative exponential curve. This is a model of a stable population. If you prey selectively only on juveniles, you get curve 2 , a high preponderance of young individuals in the population, very few middle aged and good survivorship for adults. Schedule 3 is

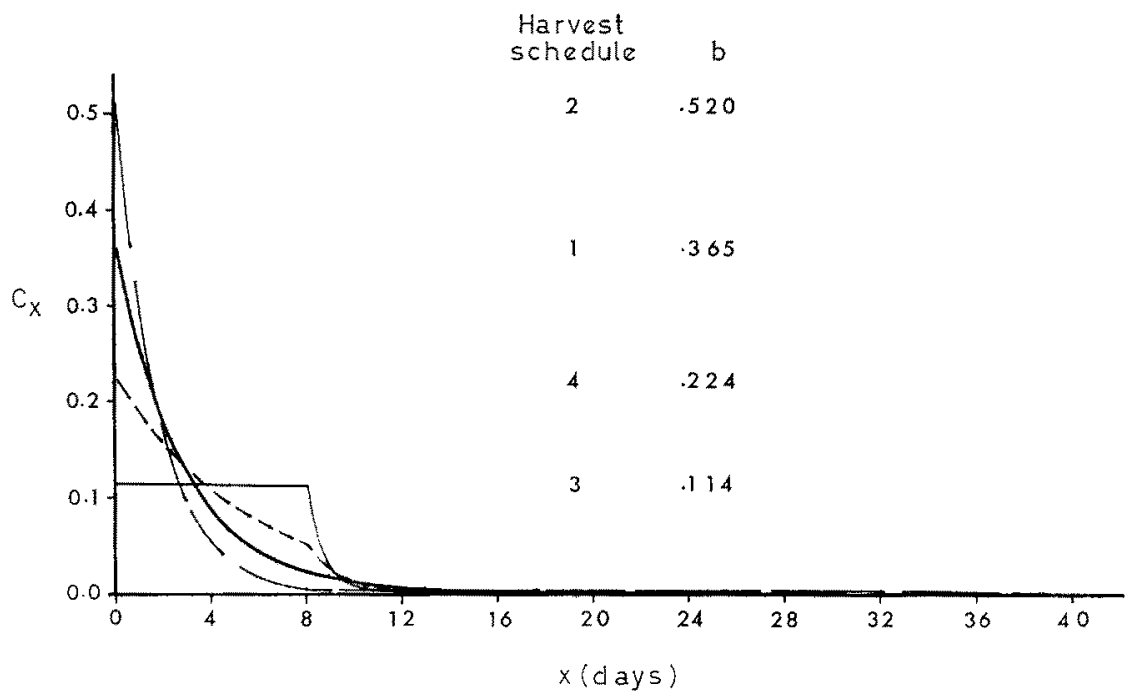

Fig. 8: Simulated age structures $\left(C_{\mathbb{X}}\right)$ of a wild population of copepods subjected to 4 schedules of harvest. Schedule $1=$ non-selective predation, schedule $2=$ removal of juveniles only, schedule $3=$ removal of adults only, schedule $4=a$ combination of schedules 1 and 3 (see text). The stable birth rate (b) was altered by the schedule of predation. $C_{x}$ is the proportion of the population that is age $\mathrm{x}$ (HeINLE)

very interesting. This was predation on adults alone and with the survival and fecundity data that I used, it was necessary to remove $148 \%$ of the adult population per day to maintain a stable population. Schedule 4 , which was intermediate between exclusively adults and the non-selective schedule, required an additional removal of $60 \%$ per day of the adults.

For quantitative comparison of age structures, the integral of $C_{x}$ is more useful than $C_{x}$. Since $\int_{0}^{\infty} C_{x}=1$, the value of the integral at any time, $x$, can be compared with the final value $(=1)$ to calculate the cumulative proportion of the population aged 0 to $x$. Even if $b$ is incorrectly estimated, the proportionality of $C_{x}$ holds, and correct percentages of age groups can be calculated. The percentages of the three age groups of copepods (nauplii, copepodids, and adults) were calculated from $\int_{0}^{\infty} C_{x}$ for each schedule of predation (Fig. 9). I have simulated very quickly on the analog computer what would take several years to do in the laboratory on the animal.

Now there is a hitch. If you go back and look at the experimental data, and it doesn't always check, this tells you that something is wrong and I think it's a quick way of finding out what is wrong. Then you must go back to the laboratory and look 
at the particular parameter that doesn't check. In the case of my laboratory cultures, the birth rate of some of the populations was so low that I couldn't in any way simulate the age structure. So more experiments were required. I'm not a mathematician but I think ecologists can use a tool like this to obtain some of the answers more quickly.


Fig. 9: Percentages of major age groups of copepods in the age structures shown in Figure 8. $\mathrm{N}=$ nauplii, $\mathrm{C}=$ copepodids, $\mathrm{A}=$ adults (HEINLE)

PAFFENhöPER: When I started growth experiments with Calanus belgolandicus, I thought that different food quantities and qualities would widely influence growth and survival. As three Chatoceros species and occasionally Skeletonema costatum were the dominant phytoplankton species in the Pacific Ocean off La Jolla, I offered these as food. Later I added Lauderia borealis and Gymnodinium splendens which occur in nature in small numbers only. In the laboratory we then found that Calanus first ate the large algae and then fed on the small organisms. I concluded that large algae occur in low numbers in the ocean because of their slow division rate and that they are more readily eaten due to their size.

HUECK: It must be kept in mind, especially with LoTKA's and VolTERra's theory, that most of the parameters used are of a descriptive nature. We should like to have stochastic models with all essential parameters known but we are still far from achieving this. But the fact that we are dealing with what is statistical in nature is also easily illustrated. It was mentioned earlier than an investigation of the index of diversity had shown that if you make your investigations over short periods of time, say every five minutes, you will find great variation. This is only natural because the index of diversity is only a stochastic entity. The expectation of a certain distribution can be a certain value but at a specific moment only one of numerous values leading to these expectations will be realized. It is quite clear that if you look at a population stochastically, at any one moment you can find that one species may be absent or present, so you should do this over a long period of time. 
Conover, R. J.: If no one has anything further to say on the subject of modelling the environment just now, I will tell a little story of my own. I was interested in trying to find a simple kind of food chain system, but also a natural food chain for experimental purposes. We have heard a lot about feeding different kinds of oceanic organisms on things like Artemia salina, the brine shrimp which they never encounter in nature.

The simple food chain with which I started to work was one involving two pteropods. Here the predator is a shell-less pteropod Clione limacina and the prey is one of two Spiratella (Limacina) species which so far as we know now are the only animal food of Clione limacina. Here I must acknowledge the contribution by my colleague Dr. Carol Lalli of McGill University who was the first to describe the very intimate

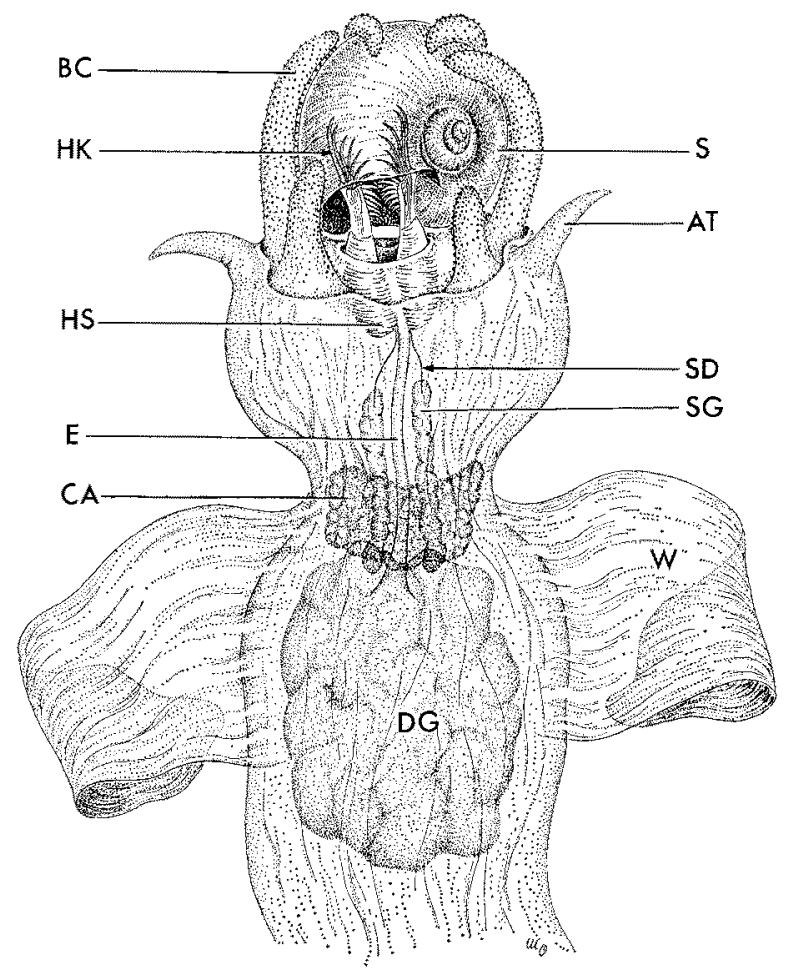

Fig. 10: Clione limacina feeding on Spiratella belicina. AT anterior tentacle; BC buccal cone; CA copulatory apparatus; DG digestive gland; E esophagus; HK hooks; HS hook sac; S Spiratella shell; SD salivary duct; SG salivary gland; W wing. (After LALLI 1970; drawn by M. OelTzSChNER) (R. J. CONOVER)

predator-prey relationship between these two species. It has been recognized for years that Clione and Spiratella frequently occurred together, but until Dr. LaLli's work (LALLi 1970), no one knew for sure what the relationship between the pteropods was or the means by which Clione acquired its nutrition. Figure 10 taken from 
Dr. Lalu's recent paper, serves to illustrate how the predation takes place. Clione limacina, as I said, is a shell-less form (gymnosome), roughly cigar-shaped, with wings (W) just behind the head. Spiratella is a shelled form (thecosome) with a sinistrally coiled shell with wings and oral apparatus normally extending out of the shell aperture. Clione limacina has two anterior tentacles (AT) and the mouth opens laterally instead of up and down. On either side of the mouth region are three pairs of buccal cones (BC) which can be hydraulically everted. When an encounter between Spiratella and Clione occurs, the cones are everted and Spiratella $(\mathrm{S})$ is seized. There is a further elaboration of the mouth parts of this organism, a pair of hook sacs (HS) which can be everted into the aperture of Spiratella. The esophagus (E) runs down between the hook sacs from the buccal cavity and there is a radula, which does not show in the figure, at the base of the hook sacs. After Clione has seized a Spiratella, it thrusts out the hook sacs, embeds the hooks (HK) into the soft parts and removes Spiratella from the shell. Then it throws the shell away. So far as we know, there is no other animal food source in the life history of Clione limacina. The veliger stage of Clione presumably eats phytoplankton, however.

In nature, the life cycles seem to be very closely interlocked so that there are small Spiratella and small Clione present at the same time and, where we are working, we feel that there may be but one generation per year of each. Admittedly, in examining oceanic plankton populations, we find very often several different size categories of each species, but possibly this is simply because the reproductive period does not occur exactly at the same time in different areas. But we do believe that any particular community of these organisms reproduces more or less simultaneously so that there is always a supply of the proper-sized prey for the predator.

This looked as though it could be a useful food chain to examine in the laboratory. The work so far is somewhat preliminary. We can take both these species into the laboratory and keep them relatively well, but we are not able to culture them. However, these organisms can be kept in the laboratory long enough to run feeding and energetic studies on them. When we started to feed Spiratella to Clione, we found a very rapid growth rate (Fig. 11). The gross growth efficiency, on a weight basis, is somewhere in the range from 40 to $80 \%$. We do not have enough information to talk about calories yet.

Because only the soft parts of the Spiratella are ingested, the only things which might not be digestible are the radula teeth of the Spiratella and some chitinous gizzard plates which help the Spiratella digest its food. Faeces produced by Clione consist of only a little dark mucous-like material. So we are considering that assimilation is $100 \%$ and, therefore, gross growth efficiency $K_{1}$ and net growth efficiency $K_{2}$ are assumed to be the same. Anyway, if we plot growth against time, for Clione fed essentially ad libitum, we get an almost straight growth curve after an initial lag as shown in Figure 11. We can get growth rates of the order of 10 to $25 \%$ per day. Under these conditions we can, in a month or so, obtain in the laboratory, a Clione big enough to become sexually mature in nature. But that's when the whole system breaks down. Now something happens. The Clione stops feeding, in some cases completely; it goes into a decline and may shrink to a small fraction of its former size. In other cases, the Clione loses considerable length and weight, and then starts to feed again (for example 
$W_{2}$ and $W_{5}$ in Fig. 11). To be sure, we are compressing the growth period, which may take months in nature, into as little as four weeks' time, but we haven't been able to get sexual maturity in these organisms even if we do these experiments at the time when the Clione are becoming sexually mature in nature. If they are ready to reproduce when captured they will lay eggs which develop to the veliger stage. We have no basis for believing that it is some nutritional factor which we are not taking into consideration which accounts for our inability to get Clione to reproduce in the lab. We

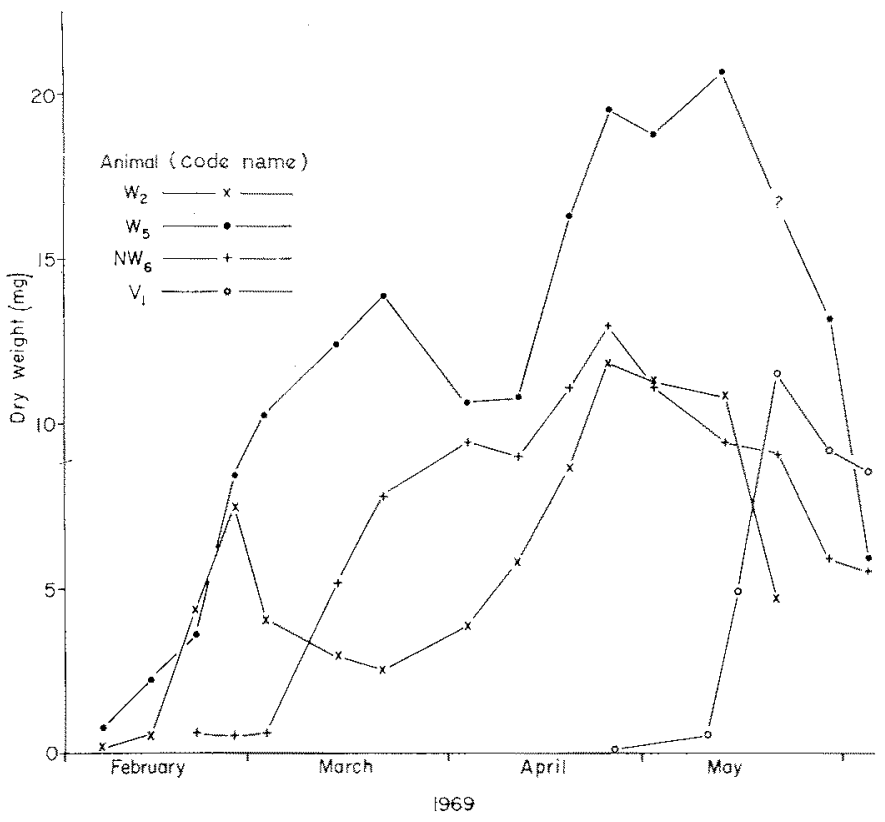

Fig. 11: Change in dry weight for several individual Clione limacina fed essentially ad libitum. Dry weight $W$ calculated from length and width measurements according to a previously determined relation $\log W=1.248 \log l+1.237 \log w-1.376$, where $l$ and $w$ equal maximum length and width in mm (excluding wings) of the body of the anesthetized Clione limacina (R. J. CONOVER)

do not know, of course, what the nutritional condition of the Spiratella is that is used as food, but we try to use freshly caught Spiratella that come from the same area where there are Clione maturing. Note also that the patterns of growth and decline do not necessarily coincide although the same Spiratella were fed to all four Clione (Fig. 11).

PAFFenhöfer: Did they feed continuously during this period on Spiratella and then reached the size at which they should mature?

Conover, R. J.: That's right.

PAfFenhöfer: I made some observations on the feeding of the colonial hydroid polyp Clava multicornis. Their food were Artemia salina larvae which had a length between 1.5 to $2.0 \mathrm{~mm}$ and were raised on Dunaliella. Clava would eat Artemia larvae 
continuously when offered in large numbers and stop only when anomalies like tentacle reduction and hydranth shrinkage began to appear due to this overfeeding. The polyps were unable to control their food uptake. They would recover when I stopped the feeding after a short period of intensive feeding but when they were fed intensively for more than 2 weeks they were unable to recover from the anomalies.

Nassogne: Permit me to show you a particular aspect of the nutrition of Euterpina acutifrons (NASSOGNE 1970). With excess food, the production of eggs in the adult life of the copepods showed large variation with type of algae. But if we give a mixture of algae, the egg production and life span is significantly different from that for each of the algae alone. When we are speaking of the effects of excess food, we should keep in mind that the animal must eat certain kinds of food to meet its nutrient requirements. It is difficult to recognize what constitutes "excess food" for a species of copepod when the life cycle is different for each type of food and different again with a mixture of foods. Perhaps this explains Dr. Paffenhören's observations. The effects of different types of foods on life cycles must be difficult to put in a computer program.

\section{USE OF CULTURES IN THE STUDY OF POLLUTION}

Conover, R. J.: Perhaps we should turn now to the important subject of pollution and its detection. Dr. Olav Skulberg has some remarks to make along these lines.

SKULBERG: Numerous environmental variables are involved in the development of natural populations and make them difficult as study objects. When using artificial populations, in field or in laboratory, the investigator exercises a certain control. The population culture is often regarded as rather a miniature analogue to a natural population. However, reservations because of manipulations of the conditions are necessary when using results from population cultures and applying them to the situation in nature.

Investigations of natural populations have raised questions as to how the ecological forces affect development. By use of experiments with population cultures analytical explanations are sought. Hence, the results have to be verified by observations of natural populations under the actual environmental conditions.

We are considering the work with plankton populations in cultures and the use of information derived from these cultures. For obvious reasons I will apply experience from my own field, biology of polluted waters, to illustrate that the experimental use of cultures in ecological studies should be extended. It is today possible to analyze reasonably both the nature and the amount of polluting substances, the soluble and unsoluble components and the contents of saprophytic and pathogenic micro-organisms. By the use of physical, chemical and biological methods in field investigations the effect of pollution to the recipients can be described. However, there is an almost complete lack of knowledge of the relationship between load of pollution and the biological response of the receiving water. For a general discussion of the subject of the use of cultures in ecological research I refer you to FogG (1965). The use of cultures specifically for detection of degree of pollution is considered in more detail in my paper (Skulberg 1967) and in Mrddlebrooks et al. (1969). 
In the present situation, with the increasing problems of waste disposal, the need for collaboration between biologists and engineers is strongly felt. Frequently, the information gained cannot easily be expressed in quantitative terms to meet the requirements of the engineer, and this is a weakness in the practical application of biological methods. Biologists have to supply biological parameters useful for the practical handling of pollution problems.

To obtain the appropriate data expressing in quantitative terms the relation between load of pollution and biological response of the receiving water, experimental work in field and laboratory seems absolutely necessary. This is indeed a challenge for experimental use of cultures.

ALEEM: I think in freshwaters these investigations seem to be more advanced than in the marine environment. Limnologists for over 15 years have tried to classify stream and pond waters according to the prevailing degree of pollution, using algal organisms as indicators. Among Chlorophyceae and Chrysophyceae certain indicator species are known to flourish in waters of specific pollution conditions. I would like to ask Dr. Skulberg if he has any information about similar indicator species in the marine environment.

SkULBerg: It is difficult to answer, but comments are possible. There has been much research on the effects of pollution in fresh waters, of course, but even for fresh water systems, the connection between load of pollution and the biological response is very badly described. With respect to indicator organisms for marine waters, I think that most of the work has been carried out with organisms from the better known taxonomic groups, which are perhaps not typical for pollution situations. When we consider fresh waters, we remember that the effect, for example, of organic pollution is a tendency toward development of communities dominated by heterotrophic species. However the heterotrophic species and the species of blue-greens, for example, are little studied for marine environments.

CoNover, R. J.: In several classic marine pollution cases, one finds very much the same kind of phenomena that one observes in fresh water. The example which comes to mind is that in Great South Bay on Long Island, N. Y., where high levels of organic matter, particularly of organic nitrogen, from the cultivation of ducks extensively carried out in the watershed, caused a very marked change in the composition and an increase in the quantity of production in the Bay with a resulting considerable decline in the natural oyster population (RYTHER 1954). I am sure that a number of cases of marine eutrophication have occurred but most of them have been little studied unless there is an economic aspect involved.

CorketT: A very short comment. I have a reference to PeArson et al. (1967) who used the Margalef diversity index for benthic animal studies in San Francisco Bay and they found a negative correlation between diversity and waste water disposal. This wasn't gross pollution, but they could show, with this index, where waste occurred at such low levels that it could not be detected without it.

WICKSTEAD: There was a small piece of information given to me which has not yet been published. When oil waste is discharged or when it is crashed on the rocks, etc. the oil film that is spread over the surface absorbs ultraviolet and in many cases 
where there is a sewage outlet there is a tremendous increase in Eschericia coli and other similar bacteria. This is an indirect effect of the pollution.

Conover, R. J.: I am not sure I understand how ultraviolet and E. coli are related here.

WICKSTEAD: Investigations have shown that when there is no pollution near sewage outlets, one gets a certain population of $E$. coli. Then along comes oil which forms a surface film over the area and this surface film absorbs the ultraviolet which had been acting as a sterilizing agent. Therefore, E. coli has a tremendous bloom in numbers after an oil spill.

\section{ARTIFICIAL SEAWATERS}

CONOver, R. J.: Several people have suggested that they would like to hear discussion of some of the problems of culturing organisms in artificial sea water. Certainly an increasing number of laboratories are in a situation where they either cannot conveniently get natural sea water or that which they can get is already badly altered by man's activities. I know that ED Zilltoux and DON HeInle have used artificial sea water to raise copepods. Would either of you care to comment on this experience?

ZnLioux: About two years ago at the National Water Quality Laboratory, I was involved in an attempt to find a single acceptable medium that would divorce us from the necessity of going out and collecting sea water. In Rhode Island the sea water was so variable that $I$ had to run a bioassay with my copepod cultures on every batch of sea water that was brought in. Even before a bioassay could be initiated, the collection and subsequent filtering of the sea water required nearly two days. About $50 \%$ of the time I found that the particular batch of sea water being tested would not sustain my cultures and I would have to go back out for repeat collections.

A number of commercial mixes and other published formulae were tested but the only one that we found that successfully maintained both copepods and phytoplankton was Triton Marine Salts. I have been working generally with a salinity of $30 \%$, but I have also used this mix up to $36 \%$ with tropical copepods. The dry salts of this commercial sea water do not enter completely into solution when mixed with distilled water. Even when it is made acid and brought up again to normal sea water $\mathrm{pH}$, some does not dissolve, although this is the fastest method of preparation and gets the largest fraction into solution. After filtration, however, there has never been any precipitation in the cultures. I have used this artificial sea water in my recirculating system up to eight months without replacement.

Conover, R. J.: Do you have any idea what this precipitate is?

Zilioux: It is not a precipitate. It is a component of the dry mix which is insoluble in water. I don't know what this residue is, but apparently the same material fails to go into solution each time. We make it up the same way every time and after filtration, nothing precipitates.

GoldIZEN: I am associated with an organization that manufactures synthetic sea water. We have the same problem. A lot of this material comes from technical grade chemicals which are used in the manufacture so that the finished product will be suffi- 
ciently inexpensive for wide use. When the mixes are made of completely reagent grade compounds, there is not nearly so much of a problem. But when some of the major components are obtained as technical grade, even with a complete analysis of what is present, some of these components are insoluble. Very frequently they are magnesium salts.

Zillioux: Contaminants which don't go into solution at all and are filtered out completely are probably of no consequence to the efficacy of the medium. If, however, the insolubles are part of the formula design, one no longer has a defined medium.

Heinle: I have used the salt that Dr. Goldizen manufactures and I would like to get a dialogue going. This is Instant Ocean. With this product we did get a precipitate and we didn't filter it. I don't know if you filter it whether you still get effective growth or not; did you filter it?

Ziluroux: Yes, I filtered Instant Ocean repeatedly, but could not stop precipitation from reoccurring.

HeInLe: You get two kinds of things; you get a flocculent, rust-colored precipitate and then there is another component that seems to form little balls. It almost looks like lipid material on the bottom of the vessel. I had an alarming experience when Dr. Goldizen wrote me and asked if I still had precipitation because they had changed the formulation. This frightened me a great deal because the material had been working fine. I would like to suggest that the companies which manufacture these things make a list of regular users so that perhaps they could be warned in advance when something is to be changed.

I grew Acartia tonsa in Instant Ocean. I grew my algae in another commercial salt, Rila Marine Mix, which has considerably more nitrate and phosphate than Instant Ocean. Then I added additional phosphate and nitrate to the point where it was toxic for the copepods, so I had to grow the algae and copepods in separate media and I had to watch that I didn't feed too much of the algae to the copepods or the nutrients would be lethal. The Rila salts themselves, apparently because of the high phosphate and nitrate content, I found not too suitable for culturing copepods. So perhaps we need at least two different types of marine salts in the system, if it is going to work effectively.

Zillioux: It might be the trace metals in your algal culture that are toxic. I find that these are very toxic to copepods at concentrations normally used in synthetic preparations for phytoplankton culture.

GILLBRICHT: We have worked with synthetic sea water in large quantities at Wilhelmshaven for more than fifteen years and we had no difficulty. We prepare our own artificial sea water rather than buy a commercially prepared solution. We also had precipitation at first, calcium sulphate and calcium carbonate, but we passed the solution through a sand filter which removed most of the precipitate. We have no difficulty otherwise.

However, there were some abnormalities in artificial sea water with respect to bacteria. You have no normal bacterial activity in artificial sea water and this means that you must use a greater quantity of water compared with the quantity of animals than if you use natural sea water. If we put some animals in a smaller quantity of water they do not like it, presumably because organic waste products accumulate; 
but if we use a greater quantity of water, the rate of breakdown of the organic compounds by the bacteria is apparently fast enough. Dr. WERNER of the Biologische Anstalt Helgoland, told me that the water from List (Sylt) near the coast is better for culturing organisms than the water from Helgoland. It may be for the same reason, more or less, because near the coast there is a greater quantity of bacteria in the water and, therefore, this water is able to break down a greater quantity of noxious organic compounds than water from Helgoland.

Conover, R. J.: This is very interesting. Why would your artificial sea water be low in bacteria?

GILLBRICHT: It is low in bacteria because initially dissolved salts have no bacteria.

Conover, R. J.: But you will get a normal bacterial flora developing in your sea water eventually.

Gillbricht: You should get a bacterial flora in time, but not at first. You do not have the normal organic compounds present. If you have some animals in the artificial sea water you may get only certain compounds produced. It may be that these special compounds don't permit the growth of the normal bacterial flora. You also have difficulty if you use too good chemicals to make your solution. You may have heavy metals in your chemicals. Therefore, we have used rough materials, the worst we could get. The results were the best.

Herring: Just two observations. I have tried using Instant Ocean for deep water decapod larvae after we brought them back from a cruise. Also I have tried a variety of oceanic plankton in Instant Ocean. It was made up according to the accompanying instructions and allowed to stand for a week or so to let the precipitate settle out. Presumably a bacterial flora developed as a result of standing for this time. It was not very successful for oceanic species, particularly for eggs of Acanthephyra, which died after about four or five days in Instant Ocean. On the other hand, Idotea pelagica and $I$. metallica, which are pretty tough animals, although oceanic species, lived very happily in Instant Ocean. I think it depends enormously on your animal. Oceanic animals, particularly, are notoriously delicate, and deep water animals even more so. Although synthetic sea waters, such as Instant Ocean, are invaluable for animals that are pretty tough to start with, if one wants to keep a delicate oceanic species in a synthetic sea water, one will have to refine the synthetic sea water very considerably.

Conover, R. J.: Refine it and add things to it. Perhaps there may be critical organic factors which are not there.

Znuloux: I certainly don't claim to have cultured Calanus but I have been able to hold individuals of this oceanic copepod in Triton for several months. Dr. RICHARD STEele at the National Marine Water Quality Laboratory in Rhode Island has also had considerable success in maintaining a phytoplankton collection of about 60 species on Triton with Guillard's F/2 enrichments. The final medium was adjusted to $25 \%$ salinity. Maintenance in Triton was successful for all species in his collection including diatoms, dinoflagellates, cryptomonads, chrysophytes, cyanophytes, chlorophytes, and one rhodophyte.

Bernhard: When I was at the Naples Laboratory, my biggest trouble was the natural sea water, so the only way to keep my algae growing was in artificial sea water. I made it up after the LEvring (1946) formula and the main problem was not 
to have too much heavy metals. Of course, you can use a little bit of EDTA and it can easily grow phytoplankton species. In the Fiascherino Laboratory we have checked out some 20 to 30 species and they all grow in artificial sea water. The problem with artificial sea water is that most of the chemicals are not pure enough and you can very easily get a high content of zinc or something like that. But we have never had an artificial sea water which did not allow our organisms to grow. We have tested our artificial sea water with sea urchin eggs (BERNHARD 1955) and phytoplankton species (BERNHARD et al. 1963). It always helps to use a little bit of some complexing substance or soil extract. I kept Cladophora for years in artificial sea water.

AleEM: In confirmation of Dr. Bernhard's statement, I found that some of the small flagellates grow better in artificial sea water than in several natural sea waters. This was artificial sea water we prepared according to the classical formula. Sometimes we add Laminaria ash or one $\mathrm{ml}$ of a mixture of trace elements to the major constituents. I refer particularly to results of experiments given in my paper during this International Helgoland Symposium (AleEM 1970).

Conover, R. J.: Dr. Goldizen, would you comment on the preparation of Instant Ocean? Are there organic materials included?

GoldizEN: The techniques for preparation are, I suppose, a trade secret, but the general methods used are certainly not. To answer your question, first about the organic materials present. We used to add the gluconate ion. This was the change that was made in the material about $1 \frac{1}{2} 2$ years ago to which Dr. HeINLE referred. We found that gluconate would support bacterial populations during storage after the material had been mixed, if it were not done under sterile conditions. I personally did not feel that gluconate added to the material at all. To make an excuse for myself, it was put into the formulation with the idea that there was something magic about organic compounds in the sea, before I ever became associated with the organization. I can't deny there are certain compounds which are useful, but not necessarily gluconate ions.

The method of manufacture for our synthetic sea water and, I suspect for many other of the commercial ones, involves using commercial blending equipment to mix together the dry components. But some of the components are present in very small quantities indeed and in order to get a degree of dispersion which would allow one to take a small amount from a large batch and have some confidence that the composition of the resulting solution would be the same from sample to sample does require the performance of some little tricks. One of these is to weigh out the minor components as dry salts, being sure they are present in a fine physical form, almost powders. These are then dispersed on a small portion of the main components such as sodium chloride crystals. Then this material is despersed in the main mass of components. We have found that this is a pretty good way of distributing the mixture evenly.

Now our particular product has the trace elements present as a solution to make sure that they are present in the correct amounts. The Triton mixture that Mr. ZrLLIOUx has mentioned here, I can't deny, is a good material. I wonder how they have managed to disperse their trace materials evenly in a small quantity of mixture. It may be that they are depending on it being carried in with one of the other components. 
BERNHARD: Do you check the chemical composition of your product or do you use a biological assay?

Goldizen: We do check it chemically. However, we do not do an analysis for every element or ion present on each batch. We also do a biological check, which perhaps is not sensitive enough for those of you who are working with phytoplankton cultures, but we work with larval development of sea urchins up to the pluteus stage. Each batch is checked in this way. It so happens that I am zoologically oriented, so I tend to use the bioassay check.

BERNHARD: What grade of chemicals are used?

Goldrzen: The major components present are what we call technical grade but we get an analysis of each batch which we purchase; of course, we purchase very large amounts. The minor components are present as reagent grade chemicals. This is not really the place to be defending a commercial product and I am not really here to sell anything. However, we find that we get large blooms of copepods in our closed systems using this material. However, this is after other organisms have been introduced, so that certain changes have obviously occurred in the culture medium.

PAFRENHÖFER: Can you give us some information about the organisms for which you designed the system?

GOLDIZEN: I am speaking more in terms of macro-organisms, large things such as anemones, star fishes, sea urchins, etc. These are the popular animals for teaching purposes.

REEVE: Have you ever thought that you might make a rather more expensive brand of Instant Ocean for people who require more constancy? Artificial sea water is so much trouble to make and we need so little of it. On the other hand, oceanic sea water is so expensive to go out and get. Perhaps you could even add certain things which people might require.

I've tried the various artificial sea waters and find that they work at least as well for the inshore plankton, especially Sagitta, as the water I get out of Biscayne Bay which is terribly variable.

Conover, S. M.: I have a comment to add about making up artificial sea waters. I was playing around with several artificial sea waters as culture media for phytoplankton last year. I was interested in cold sterilization methods and started using some of the dialysis membranes. I made up a fairly simple artificial sea water, staying away from as many organics as possible so that the only organic compounds added were small amounts of vitamins and citric acid, but no EDTA or chelators of this sort. It was essentially a modification of TAYLOR's medium (TAYLOR 1964) and was made up in a special carbon-free distilled water. I found that my phytoplankton grew very well until I passed the entire medium through a 50,000 molecular weight dialysis membrane. After I did this nothing grew. My guess, and its nothing more than this, is that possibly there were impurities of some sort in the reagents, apparently quite large molecules or small aggregates, which provided some necessary component to sustain algal growth and these were retained by the dialysis membrane. Even though I thought I had made a well-defined medium in which all the components would pass through the dialysis membrane, I inadvertently added some growth factor that would not pass 
through. Here is something to watch if you go into cold sterilization methods, and also something to bother you in making a really carefully defined medium.

BernhARD: Artificial sea water is not very difficult to make if you prepare a little bit at a time. If you make stock solutions of single salts and then just pipet out the proper amount you can make artificial sea water in half an hour. We have found that if you use soil extract to keep your stock phytoplankton cultures, you just have to add five basic salts and some phosphate and nitrate.

We discovered another thing about artificial sea water, while working on the uptake of zinc. We wanted some sea water which had no organic material. We used a polarograph to determine the ionic zinc (MACCHI 1965) and then added chelating resin to get total zinc and we found that we had much more complexed zinc in the artificial sea water than we had in the natural sea water. I think this can be explained because everyone is using detergents for cleaning their vessels including the manufacturer. We found that we had 300 micrograms of zinc complexed in the artificial sea water which we thought had no organic substance in it.

To get sea water or any solution without any organic material, you have to heat all your salts to destroy all the organic material. It is difficult to get sea water without organic material. We must go to quite a lot of trouble beginning with distilling the water. You can't use resins because resins leach some organic materials too. If someone really wants to see that he has no organic complexing agents, I can recommend that he check his solution with a polarograph. If there are any complexing agents present they will immediately bind up any ionic metal added, which will show clearly in the polarographic determinations.

Droop: With regard to the destruction of your medium when you pass it through a dialysis bag, as a possibility, you had iron and silicon in this water?

Conover, S. M.: Yes.

Droop: You see, once you put iron and silicon into your medium there is a continual rain of aggregates and a lot of things are absorbed onto these.

Conover, S. M.: That's certainly possible.

Droop: And I agree with you: it is very difficult to make a naturalistic artificial sea water!

Heinle: Dr. Bernhard, I wonder whether adding soil extract is good for all of us if we are really interested in defined nutrition. Soil extract is perhaps not well enough defined.

BeRnHARD: No. I use it just for the maintenance of cultures. I had so much trouble with the sea water at Naples that, in order to keep my culture collection going, I used soil extract and simple artificial sea water. I agree with Dr. Droop that it is difficult to make a carefully defined artificial sea water.

GILLBRICHT: We must keep in mind that in aquariums we never have correct sea water, even if we start with a natural sea water. For instance, if you use a sand filter, it gives off great quantities of calcium while, at the same time, the alkalinity is destroyed by the animals. Starting with natural sea water in our aquaria we have observed a calcium content up to five times higher than normal.

Conover, R. J.: There do seem to be a number of unsolved technical problems in the use of artificial sea water so we may have to use the ocean for some organisms for 
a while longer. I wonder if there are some other technical problems that we might discuss. Some of us perhaps have tricks or devices that we use in our culture work that others would like to know about. Yesterday Dr. Paffenhöfer mentioned the stirring mechanism he used for his copepod cultures. I am wondering if he would care to elaborate on this a little bit more, as some of us didn't really understand it at the time.

\section{COPEPOD CULTURE}

PAFFENhöfer: The cultivation method which I mentioned in my talk was used to rear Calanus belgolandicus from the moment the nauplii hatched to the time when they reached adulthood. When I started to culture Calanus I agitated the culture beakers, which were standing in diffused light, six to ten times per day; this, however, did not keep the phytoplankton constantly in suspension. Finally I found that a certain kind of rotation resulted in an even suspension of the phytoplankton cells: The bottom of the beaker rotated in a wide circle, the upper part of the beaker in a small circle around an imaginary axis with the beaker hanging on an universal joint (Fig. 12; see also Fig. 1 in PAfFenhöfer 1970, p. 347).

The container size ranged from $3,000 \mathrm{ml}$ beakers to $8,000 \mathrm{ml}$ jars. I offered as food mostly chain-forming diatoms. The water movement caused by the rotation did not break the chains which had approximately the same length as those collected in the Pacific Ocean off La Jolla (mostly 4 to 10 cells per chain). I took samples from different locations in the beakers and counted their numbers and sizes with a Coulter Coun$\operatorname{ter}^{\circledR}$ Model A; the counts and the size distributions were the same, which means that the phytoplankton was evenly distributed. The fecal pellets settled at the centre of the bottom of the beaker. Thus Calanus belgolandicus, as they were mostly swimming, encountered only living phytoplankton. Occasionally, when the food concentration was very low, Calanus started feeding on the fecal material. Only the dinoflagellate Gymnodinium splendens sometimes showed an uneven distribution, concentrating close to the surface in attraction to the light. Therefore, those Calanus cultures feeding on G. splendens were gently agitated with a glass rod at intervals of 8 to 10 hours.

Conover, R. J.: How rapidly do you rotate the device?

PAFfenhörer: The rotation speed was almost always 2.0 revolutions per minute except for Gymnodinium splendens where it was 0.5 to 1.0 r.p.m.

I would like to make some comments on the chain sizes of the diatoms which served as food for Calanus belgolandicus. 20 to 40 Lauderia borealis chains were equivalent to 50 micrograms $\mathrm{C} / \mathrm{l}$ which is close to the average phytoplankton concentration in the ocean off I $\lrcorner$ a Jolla. The chains ranged mostly from 4 to 14 cells. Samples from the ocean had often 10 cells per chain. The Lauderia chains in agitated cultures reached a maximum length of $1 \mathrm{~mm}$, in unagitated cultures 4 to $5 \mathrm{~mm}$.

The Chaetoceros curvisetus chains often had a spherical shape with a diameter up to 200 microns and a maximum of 230 cells per sphere. Skeletonema costatum chains had a maximum of 14 to 16 cells. Sheldon \& Parsons (1967) caught Chaetoceros socialis with an average of 30 cells per chain. MARshall \& ORR (1930) found 
that Skeletonema costatum, which served as the main food for Calanus finmarchicus in the area investigated, generally had 10 cells per chain.

Zrulioux: What effect did chain length have on the feeding rate of your copepods?

PAFFenhöfER: When Calanus belgolandicus encountered Chaetoceros curvisetus as long chains or even spheres, they grazed at a far higher rate than when feeding on

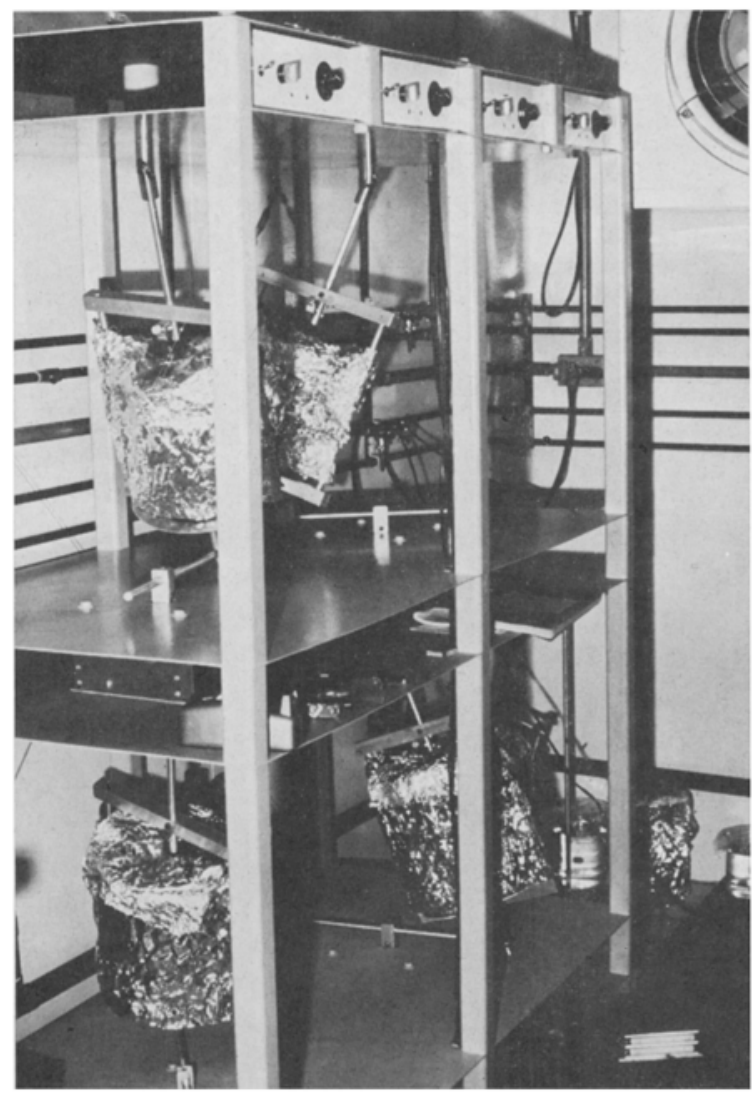

Fig. 12: Culture apparatus used for Calanus belgolandicus (PAFFENHÖFER)

the same species with only 2 to 6 cells per chain. The same was observed for Skeletonema costatum and Lauderia borealis.

ALEEM: Is it just that bigger chains are easier to catch?

PAFFENhöfER: When the food consists of small particles, Calanus belgolandicus filters, but it appears to grasp single particles when it encounters large diatoms like Coscinodiscus wailesii. Preliminary studies which were carried out under the direction of Dr. John STRICKLAND showed that Calanus belgolanaicus females first ingested all those Coscinodiscus wailesii cells which had a diameter of $220 \mu$ before they started eating cells of the same species which had a diameter of 70 to $100 \mu$. There must be 
some sensory mechanism which enables Calanus helgolandicus to differentiate between large and small particles.

Zillioux: In feeding experiments with Acartia clausi, I took long chains of Skeletonema costatum, up to 14 cell/chain, and broke them up by using an ultrasonic disintegrator at low output. I found that the number of cells ingested per hour by Acartia increased by $56 \%$ when the Skeletonema chains were reduced to one to five cells in length.

This difference in food size "preference" between Calanus belgolandicus and Acartia clausi supports other evidence I am finding which indicates that these "preferences" are quite specific for species as well as for the particular life stage. It appears that optimal feeding (that is, the maximum utilization of a given food source) for at least some species requires the availability of food within a rather narrow size range.

\section{MEASURING FEEDING RATES AND NUTRITIONAL SUITABILITY OF FOOD SOURCES}

HerRING: Most of the preceding comments have been concerned with feeding filter-feeders on diatoms or other phytoplankton cultures. Some of us use live animals as food for larvae or plankton predators and this presents more difficulties in that the prey animals, usually Artemia salina, have their own behaviour patterns and reactions. The problem is to know when the amount of food you put in is sufficiently available for the animal which you are trying to feed. With phytoplankton as a food source you can presumably tell this very simply but it is not so easy when the food is a swimming zooplankter. Dr. Bookнout, perhaps you have some suggestions.

BookHout: We are concerned about this ourselves. If we could obtain an apparatus similar to the one SHELBOURNE and associates use at Lowestoft, a modification of the Coulter Counter, we would like to set up an experiment to determine the effect of various numbers of Artemia nauplii on crab development. The optimum number of Artemia nauplii would be the number beyond which no faster growth or better development would occur. Fractions of this amount, $3 / 4,1 / 2,1 / 4$, etc., should be fed to determine the effects of a reduced diet on crab development. We would like to see an experiment of this sort performed.

REEVE: In the case of Sagitta bispida, a carnivorous zooplankter, I counted the number of Artemia salina it would eat over a 24 hour period. You get just exactly the same sort of curve plotting the rate of feeding against concentration of Artemia that you get with copepods or, for that matter Artemia itself, feeding on phytoplankton. There is a food level at which maximum ingestion is reached. I did not get the food level to the concentration where feeding may start to go down again as has been observed for some copepods. I used as a rule of thumb for optimum feeding a concentration where food was reduced by no more than $50 \%$ in a 24 hour period. If you put the concentration at some level where there is little or no reduction in amount of food by the predator you may be approaching a level where something nasty may happen such as the build-up of noxious organic metabolites or bacteria.

Droop: Orr and MArshall some years back labelled algae and fed them to a 
herbivore, which in this case was my bug, Oxyrrbis marina, and then used Oxyrrbis as a food for Calanus. This seems to be a technique which could be applied to many systems to give you a ready measure of utilization.

Conover, R. J.: There are problems envolving recycling and reaction kinetics associated with using isotopes for the quantitative measurement of food ingested or assimilated. From a qualitative point of view, this technique would certainly tell whether the organism was being ingested but I am not at all sure that you would be able to ascertain the optimum food level.

Greve: I would like to make a short comment on feeding carnivorous zooplankton species with Artemia salina. I have tried some experiments in the double cuvette with Artemia on one side and different species of zooplankton on the other as food for Pleurobrachia pileus. In contrast to some copepods, Artemia keeps swimming in one direction and does not avoid the tentacles of Pleurobrachia or have the strength to break away when caught. Even at concentrations of Artemia much lower than those of the copepods, a considerably higher number of Artemia were caught and eaten by the ctenophores. Many were spit out again because the ctenophores just fed on and on. In about two hours the cuvette was empty of Artemia, most of which had been in the pharynx of Pleurobrachia and out again, only the last few being retained inside; in the same length of time, only a very few copepods, even though offered at the same or higher concentrations, were taken up by Pleurobrachia. So you can't really equate the number of Artemia eaten with the number of copepods eaten, and you also have to remember that there is a very different behaviour in the different species used for food.

The determination of the number eaten is very difficult. I have tried to do this by taking photographs of the cuvettes at different times and then counting the organisms on the photographs. I have also tried to employ an electronic arrangement to scan the photographs in order to avoid counting "by hand".

PAFFenhörer: I would like to make some remarks on the food level necessary to initiate or to maintain feeding of herbivorous copepods. Adams \& STEELE (1966) carried out shipboard experiments with Calanus finmarchicus and Calanus belgolandicus using different life stages by feeding them natural phytoplankton from the North Sea. They used for these grazing experiments containers which ranged in size from 180 to $1,000 \mathrm{ml}$ and found that feeding stopped at phytoplankton concentration of $70 \mu \mathrm{g} \mathrm{C} / 1$ or below. Parsons et al. (1969) made similar investigations with Calanus plumchrus and Calanus pacificus feeding on natural phytoplankton in $1,000 \mathrm{ml}$ containers. In this case feeding ceased at $40 \mu \mathrm{g} \mathrm{C} / 1$.

My growth experiments with Calanus belgolandicus were carried out in jars which contain up to $7,000 \mathrm{ml}$ of seawater. Depending on the size of the food particle Calanus repeatedly grazed the phytoplankton down to levels between 20 and zero $\mu \mathrm{g} \mathrm{C/l}$. There may be several reasons why Calanus continued to feed at those low phytoplankton concentrations. Firstly, the copepods were adapted to a certain food level which could differ from one experiment to another. Secondly, the size of the containers could influence the copepods' behaviour. They were able to move more freely in $7,000 \mathrm{ml}$ jars than in $1,000 \mathrm{ml}$ beakers. Thirdly, the size and shape of the phytoplankton was important: The smaller the food particle the lower the grazing rate of Calanus. Furthermore, the stage and, therefore, the size of Calanus should be con- 
sidered. I found that the young copepodite stages (I, II and III) could graze more effectively on Skeletonema costatum ( 5 to $8 \mu$ diameter) than copepodite stage $\mathrm{V}$ and females were able to do.

Zillioux: I must go back to comment on Dr. CONOVER's remark concerning the use of radio isotopes to measure feeding. I have been able to determine optimal feeding with Acartia clausi using ${ }^{14} \mathrm{C}$ labelled Rhodomonas baltica. Over a range of concentrations from 5,000 to 50,000 cells $/ \mathrm{ml}$, the feeding rate continues to increase but over



Fig. 13: Effect of food concentration (Rhodomonas baltica) on ingestion by Acartia clausi adult females (Zislioux)

50,000 cells $/ \mathrm{ml}$ a plateau is reached (Fig. 13). I have also measured the assimilation value with this particular alga and it is uniformly high no matter what the food concentration is. At a level of about $50,000 \mathrm{cells} / \mathrm{ml}$ the animal apparently is satiated and the ingestion rate does not increase with any further increase in Rhodomonas concentration.

Conover, R. J.: Are you examining the uptake by the body or the loss from the culture?

ZrLlıoux: I am examining the uptake.

Conover, R. J.: This is where you can run into trouble. You get the same kind of curve as the concentration of label inside the animal and out approach the same level, that is, as the animal becomes uniformly labelled.

Zillioux: These are individual experiments at different concentrations. The experiments are run for exactly $1 \mathrm{~h}$ at $10^{\circ} \mathrm{C}$ which is less than the time from ingestion to defecation at that temperature.

Conover, R. J.: If you use an isotope such as ${ }^{32} \mathrm{P}$ in the same way as Rigler (1961) did, that is, feeding for a very short period of time so as to keep excretion to a minimum, you are approaching an accurate measure of ingestion. But some assimilation does occur during this time, no matter how short and as soon as ${ }^{14} \mathrm{C}$ is assimilated some of it may be respired. 
ZrLloux: I agree that I am probably losing some label respired ${ }^{14} \mathrm{CO}_{2}$, but in the short period of my experiment, I doubt this loss would significantly alter the results.

GolD: I would like to refer to some work on the tintinnids that I have done to see whether or not a labelled food was utilized, by detecting the label in the lorica (GoLD 1969). This would, of course, tell whether some metabolism was going on. Another way is to introduce the food and permit grazing to go on at various food levels and then measure the amount of the algal population that remains by means of isotopes. In this way you measure decrease or death of the algal cells. This can be done in a very short period of time.

Conover, R. J.: The difficulty is in designing a grazing experiment in which you can get a large enough change in a short enough time.

Gold: Tintinnids are very active, especially the large one and you can treat them in this way.

Conover, R. J.: The counting techniques are so much better than they used to be that it is much easier today to perform the experiment as you describe.

BERNHARD: If you label with two isotopes you will probably have a check on recycling characteristics. Zinc is not very easily lost from phytoplankton cultures. If you have no complexing agent in your sea water, then you can probably check your carbon label with the zinc label.

Conover, R. J: : Excretion of ${ }^{65} \mathrm{Zinc}$ has been used as an indicator of metabolism by certain people; that is, the rate of loss of zinc seems to be correlated with the respiratory rate. We really need a label that stays permanently.

I am sorry to have to terminate this discussion but it is getting near the end of the day. Perhaps we have not solved all the major problems of plankton cultivation, but the session has yielded a number of ideas which I am sure will be useful to us all. Thank you all for coming and sharing your problems and solutions with us.

\section{LITERATURE CITED}

Adams, J. A. \& Steele, J. H., 1966. Shipboard experiments on the feeding of Calanus finmarchicus (GunNerus). In: Some contemporary studies in marine science. Ed. by $H$. Barnes. Allen \& Unwin, London, 19-35.

Aleem, A. A., 1970. Potential bioassay of natural seawaters and influence of certain trace elements on the growth of phytoplankton organisms. Helgoländer wiss. Meeresunters. 20, $229-248$.

Bernhard, M., 1955. Die Kultur von Seeigellarven (Arbacia lixula L.) in künstlidem und natürlichem Meereswasser mit Hilfe von Ionenaustauschsubstanzen und Komplexbildnern. Pubbl. Staz. zool. Napoli 29, 80-95.

- Boffi, V., Lucarelli, A., Rampi, L., Melchiorri-Santolini, U. \& Benedetti, A., 1963. Rapporto sull'attivitá scientifica e tecnica del Laboratorio per lo Studio della Contaminazione Radioattiva del Mare. CNEN Technical report RT/BIO (Rome) 63 (8).

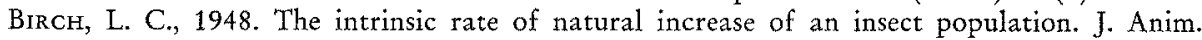
Ecol. 17, 15-26.

BRAARUd, T, 1962. Species distribution in marine phytoplankton. J. oceanogr. Soc. Japan 20, $628-649$.

Cusming, D. H., 1959. On the nature of production in the sea. Fishery Invest., Lond. (Ser. 2) $22(6), 1-40$. 
- 1963. Studies on a Calanus patch. V. The production cruises in 1954: summary and conclusions. J. mar. biol. Ass. U.K. 43, 387-389.

Droop, M. R., 1966. Vitamin $B_{12}$ and marine ecology. III. An experiment with a chemostat. J. mar. biol. Ass. U.K. 46, 659-671.

- 1968. Vitamin $\mathrm{B}_{12}$ and marine ecology. IV. The kinetics of uptake growth and inhibition in Monocbrysis lutheri. J. mar. biol. Ass. U.K. 48, 689-733.

FoGG, G., 1965. Algal cultures and phytoplankton ecology. Univ. Wisconsin Press, Madison, $126 \mathrm{pp}$.

GoLD, K., 1969. Tintinnida: Feeding experiments and lorica development. J. Protozool. 16, 507-509.

- \& BAREN, C. F., 1966. Growth requirements of Gyrodinium cobnii. J. Protozool. 13, 255-257.

Hamilton, R. D. \& Preslan, J. E., 1969. Cultural characteristics of a pelagic marine hymenostome ciliate, Uronema sp. J. exp. mar. Biol. Ecol. 4, 90-99.

HeInLE, D. R., 1970. Analog simulation of population age structures. Tech. Report, Univ. of Maryland Water Resources Research Center.

Herbert, D., 1958. Some principles of continuous culture. Int. Congr. Microbiol. 7 (Stockholm), 381-396.

Hustedt, F., 1930. Die Kieselalgen Deutschlands, Osterreichs und der Schweiz. In: Kryptogamen-Flora. Hrsg. von L. RabenHoRst. Akad. Verl. Ges., Leipzig, 7( T. 1), 1-920.

LALLI, C. M., 1970. Structure and function of the buccal apparatus of Clione limacina (Phipps) with a review of feeding in gymnosomatous pteropods. J. exp. mar. Biol. Ecol. 4, 101-118.

LEsLie, P. H. \& RANSON, R. M., 1940. The mortality, fertility, and rate of natural increase of the role (Microtus agrestis) as observed in the laboratory. J. Anim. Ecol. 9, 27-52.

Levring, T., 1946. Some culture experiments with Ulva and artificial seawater. K. fysiogr. Sällsk. Lund Förh. 16, 45.

LotKA, A. J., 1925. Elements of Physical Biology. Williams \& Wilkins, Baltimore, $460 \mathrm{pp}$.

MAcCHI, G., 1965. The determination of ionic zinc in seawater by anode stripping voltametry using ordinary electrodes. J. electroanal. Chem. 9, 290-298.

Margalef, R., 1968. Perspectives in ecological theory. Univ. Chicago Press, Chicago, 111 pp.

Marshall, S. M. \& ORR, A. P., 1930. A study of the spring diatom increase in Loch Striven. J. mar. biol. Ass. U.K. 16, 853-878.

Mrdolebrooks, E. J., Maloney, T. E., Powers, C. F. \& KaAck, L. M., 1969. Proceedings of the eutrophication - biostimulation assessment workshop. Federal Water Pollution Control Adm., Corvallis, $281 \mathrm{pp}$.

NAssogne, A., 1970. Influence of food organisms on the development and culture of pelagic copepods. Helgoländer wiss. Meeresunters. 20, 333-345.

Paffenhörer, G. A., 1970. Cultivation of Calanus helgolandicus under controlled conditions. Helgoländer wiss. Meeresunters. 20, 346-359.

Parsons, T. R., Lebrasseur, R. J., Fulton, J. D. \& Kennedy, O. D., 1969. Production studies in the Strait of Georgia. II. Secondary production under the Fraser River Plume, February to May, 1967. J, exp. mar. Biol. Ecol. 3, 39-50.

Pearson, E. A., Storrs, P. N. \& Selleck, R. E., 1967. Some physical parameters and their significance in marine waste disposal. In: Pollution and marine ecology. Ed. by T. A. Olson \& F. J. Burgess. Interscience Publishers, New York, 297-315.

PRATT, D. M., 1966. Competition between Skeletonema costatum and Olisthodiscus luteus in Narragansett Bay and in culture. Limnol. Oceanogr. 11, 447-455.

Pritchard, D. W., 1967. Observations of circulation in coastal plain estuaries. In: Estuaries. Ed. by G. H. Laufr. Publ. Am. Ass. Advmt Sci. 83, 37-44.

RigLer, F. H., 1961. The relation between concentration of food and feeding rate of Daphnia magna Straus. Can. J. Zool. 39, 857-868.

RyTHER, J. H., 1954. The ecology of phytoplankton blooms in Moriches Bay and Great South Bay, Long Island. N. Y. Biol. Bull. mar. biol. Lab., Woods Hole 106, 198-209.

SHELDON, R. W. \& PARsons, T. R., 1967. A continuous size spectrum for particulate matter in the sea. J. Fish. Res. Bd Can. 24, 909-915. 
Skulberg, O., 1967. Algal cultures as a means to assess the fertilizing influence of pollution. Water Pollution Control Federation, Washington, D.C., 113-127.

SMAYDA, T. J., 1969. Experimental studies on the influence of temperature, light and salinity on cell division of the marine diatom, Detonula confervacea (Cleve) Gran. J. Phycol. 5, $150-157$.

TAYLOR, W. R., 1964. Inorganic nutrient requirements for marine phytoplankton organisms. Occ. Publs. Narragansett mar. Lab. 2, 17--24.

ZnLlioux, E. J., 1969. A continuous recirculating culture system for planktonic copepods. Mar. Biol. 4, 215-218.

- \& LACKIE, N. F., 1970. Advances in the continuous culture of planktonic copepods. Helgoländer wiss. Meeresunters. 20, 325-332.

\section{LIST OF PARTICIPANTS}

AleEm, A. A., Laboratory of Oceanography, University of Alexandria; Alexandria, Egypt.

BERNhARD, M., Laboratorio Contaminazione Mare, CNEN-EURATOM; Fiascherino-La Spezia, Italy.

BoALch, G. T., Marine Biological Association of the United Kingdom, The Laboratory, Citadel Hill; Plymouth, England.

Bоокноч', C. G., Duke University, Marine Laboratory; Beaufort, N.C. 28516, USA.

Conover, R. J., Marine Ecology Laboratory, Bedford Institute; Dartmouth, Nova Scotia, Canada.

Conover, S. M., Institute of Oceanography, Dalhousie University; Halifax, Nova Scotia, Canada.

CoRketT, C., Department of Zoology, Bristol University; Bristol, England.

Costlow, J. D., Jr., Duke University, Marine Laboratory; Beaufort, N.C. 28516, USA.

Droop, M. R., Scottish Marine Biological Association, Marine Station; Millport, Isle of Cumbrae, Scotland.

Gillbricht, M., Institut für Hydrobiologie und Fischereiwissenschaft der Universität Hamburg; Hamburg 50, Palmaille 9, FRG.

Gold, K., Osborn Laboratories of Marine Sciences. New York Aquarium, Boardwalk \& W. 8 th Street; Brooklyn, N.Y. 11224, USA.

Goldizen, V. C., Aquarium Systems, Inc., 1450 East 289th Street; Widkliffe, Ohio 44092, USA.

Greve, W., Biologische Anstalt Helgoland, Meeresstation; Helgoland, FRG.

HALlDal, P., Biologiska Institutionen, Umeå Universitet; Umeå, Sweden.

HeInle, D. R., University of Maryland, Natural Resources Institute, Chesapeake Biological Laboratory, Box 38; Solomons, Md. 20688, USA.

Herring, P. J., National Institute of Oceanography; Wormley, Godalming, Surrey, England.

Hueck, H. J., Centraal Laboratorium TNO, P.O. Box 217; Delf, Netherlands.

NAssoGNE, A., Laboratorio Contaminazione Mare, CNEN-EURATOM; Fiascherino-La Spezia, Italy.

PAFFENHöFrer, G.-A., University of California, San Diego, Institure of Marine Resources, P.O. Box 109; La Jolla, Calif. 92037, USA.

ReEve, M. R., Institute of Marine Sciences, University of Miami, 10 Rickenbacker Causeway; Miami, Fla. 33149, USA.

Skulberg, O., Norsk Institutt for Vannforskning, Gaustadalleen 25; Blindern, Oslo 3, Norway.

SMAYDA, T., Graduate School of Oceanography, University of Rhode Island; Kingston, R.I. 02881, USA.

Tranter, D., Indian Ocean Biological Centre, Pullepaddy Cross Road; Ernakulum, Cochin-18, India.

Wickstead, J. H., Marine Biological Association, The Laboratory, Citadel Hill; Plymouth, England.

Ziltroux, E., Institute of Marine Sciences, University of Miami, 10 Rickenbacker Causeway; Miami, Fla. 33149, USA. 